\title{
The Effects of Projected Future Demand Including Very Light Jet Air-taxi Operations on U.S. National Airspace System Delays as a Function of Next Generation Air Transportation System Airspace Capacity
}

\section{JULY 2007}

\author{
Jerry Smith and Jeff Viken* \\ NASA Langley Research Center, Hampton, VA, 23681
}

Samuel Dollyhigh*

Swales Aerospace, Langley Research Center, Hampton, VA 23681

Antonio Trani", Hojong Baik*, Nicholas Hinze ${ }^{\otimes}$, Senanu Ashiabor ${ }^{\%}$ Virginia Polytechnic Institude and State University, Blacksburg,, VA, 24061

* Senior Research Engineers, Systems Analysis Branch, NASA Langley Research Center, Hampton, Virginia, 23681.

* Senior Research Engineer, Swales Aerospace, NASA Langley Research Center, Hampton, VA, 23681, Associate AIAA Fellow

• Associate Professor, Department of Civil and Environmental Engineering, Patton Hall 200, Virginia Tech, Virginia, 24061, AIAA Senior Member.

• Research Assistant Professor, Department of Civil and Environmental Engineering, Patton Hall 200, Virginia Tech, Virginia, 24061.

${ }^{\otimes}$ Research Associate, Department of Civil and Environmental Engineering, Patton Hall 200, Virginia Tech, Virginia, 24061.

${ }^{\%}$ Graduate Research Assistant, Department of Civil and Environmental Engineering, Patton Hall 200, Virginia Tech, Virginia, 24061. 


\section{Introduction}

This paper presents the results from a study that investigates the potential effects of the growth in air traffic demand including projected Very Light Jet (VLJ) air-taxi operations adding to delays experienced by commercial passenger air transportation in the year 2025. The geographic region studied is the contiguous United States (U.S.) of America, although international air traffic to and from the U.S. is included.

The main focus of this paper is to determine how much air traffic growth, including VLJ air-taxi operations will add to en-route airspace congestion and determine what additional airspace capacity will be needed to accommodate the expected demand. Terminal airspace is not modeled and increased airport capacity is assumed.

Sections II to $\mathrm{V}$ of this paper are related to demand forecasting and generation of a future flight schedule and include a discussion of typical VLJ operating characteristics in section III. Section VI briefly describes some features of capacity enhancing concepts, although no specific concept is modeled for this study. Section VII describes the airspace simulation used. The results from simulation are in section VIII, where delays, airspace sector loading and numbers of conflicts between aircraft are analyzed. The conclusions follow in section IX.

\section{Growth in Demand for Air Transportation}

Demand for air transportation in the U.S is expected to increase the number of passenger enplanements by a factor of two by the year 2025 according to data extrapolated from FAA forecasts [1]. The U.S. transportation system is already under considerable stress with delays estimated to cost airlines $\$ 5.9$ billion in 2005 [2]. Without transformation, the current National Airspace System (NAS) will be incapable of meeting future demand.

The VISION 100 - Century of Aviation Reauthorization Act (P.L.108-176) sets out the mandate for the Next Generation Air Transportation System (NextGen formerly NGATS) and proposed a public/private partnership managed by the Joint Planning and Development Office (JPDO) to carry it out. The JPDO is a coalition of government agencies and private partners that includes the Departments of Transportation, Defense, Homeland Security and Commerce, the FAA, NASA and White House Office of Science and Technology Policy, members of the aviation industry and users of the air transportation system. The JPDO is developing a Concept of Operations (CONOPS) [3] for NextGen. The final version of the CONOPS will provide an overall, integrated view of NextGen operations in the 2025 timeframe, including key transformations from today's operations. 
Figure 1 shows the FAA forecast growth from 2004 to 2020, extrapolated to 2025. The year 2004 has been defined by the JPDO as the baseline year and 2025 is the goal year for NextGen.

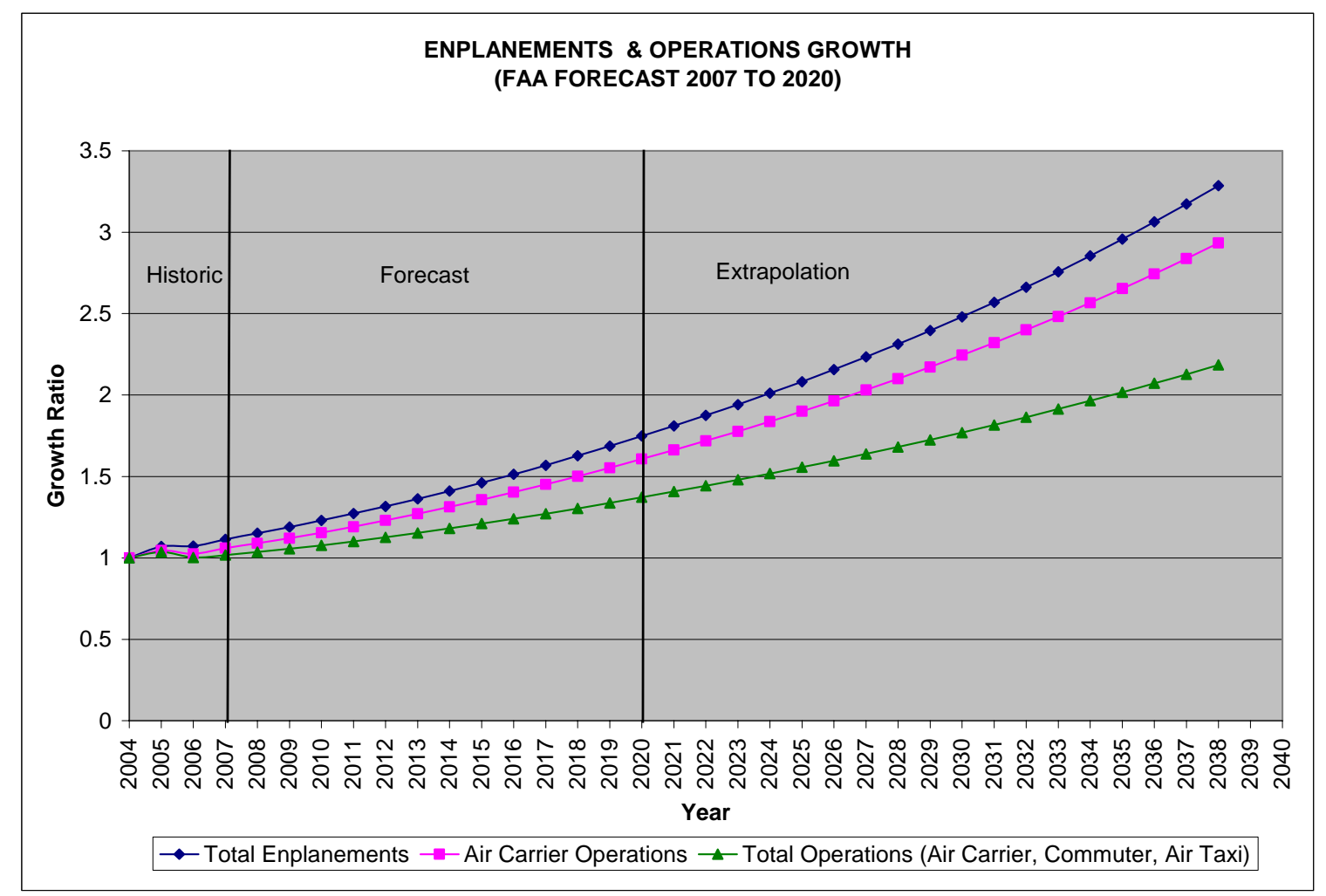

Figure 1. Forecast Growth in Passenger Air Transportation

The FAA forecast contains data for total passenger enplanements and operations data for different categories of aircraft. Air Carrier operations are for commercial aircraft with capacity of more than 60 seats. Commuter operations are for aircraft with 60 or fewer seats on scheduled flights. Air-taxi operations are for aircraft with 60 or fewer seats on non-scheduled or for-hire flights. Commuter/Air-taxi operations are combined as one category.

Although passenger enplanements are forecast to double from 2004 to 2025, based on extrapolation from the FAA forecast, aircraft operations are projected to increase by less than that factor. Air Carrier operations are projected to increase by a factor of 1.9 and total operations by a factor of 1.56 in the year 2025 .

The operations growth is less than the enplanements growth because the FAA forecast includes an increase in the passenger average load factor and a significant increase in regional jet size. In 2004 the typical average load factor was 76\% of seats filled, this is forecast to increase to $80.3 \%$ by 2020 and $80.5 \%$ extrapolated to 2025 . Regional jet size was typically 48 seats in 2004 and is forecast to increase to 59 seats in 2020 and 62 seats extrapolated to 2025. Regional jet traffic is the largest single category of commercial aircraft used in the U.S. The FAA forecasts this category of traffic to continue to grow at 
a faster rate than larger Air Carrier aircraft. Since these aircraft are forecast to take an increasing proportion of air traffic and are increasing in size, total operations growth is significantly less than the growth in enplanements. The growth in Air Carrier operations increases more in line with enplanements and the bulk of these Air Carrier operations will take place at larger more congested airports.

\section{Very Light Jets}

VLJs are turbofan-powered aircraft that are smaller, have somewhat lower performance and are lower in cost than the typical business jets of today.

The National Business Aviation Association (NBAA) defines the VLJ category as consisting of jet aircraft weighing 10,000 pounds or less - a distinction from the traditional definition of light aircraft weighing 12,500 pounds or less, and large aircraft weighing more than 12,500 pounds.

Table 1 shows operating characteristics for selected VLJ aircraft. The Eclipse 500 and Cessna Citation Mustang have achieved production certification. Eclipse and Cessna have started delivery of the first aircraft to customers.

\begin{tabular}{|l|l|l|l|l|}
\hline & Eclipse 500 & $\begin{array}{l}\text { Adam Aircraft } \\
\text { A700 }\end{array}$ & $\begin{array}{l}\text { Cessna } \\
\text { Citation } \\
\text { Mustang }\end{array}$ & $\begin{array}{l}\text { Embraer } \\
\text { Phenom 100 }\end{array}$ \\
\hline $\begin{array}{l}\text { Passenger } \\
\text { capacity }\end{array}$ & $4-5$ & $4-5$ & $4-5$ & $4-5$ \\
\hline $\begin{array}{l}\text { Maximum } \\
\text { cruise speed } \\
\text { (knots) }\end{array}$ & 375 & 340 & 340 & 380 \\
\hline $\begin{array}{l}\text { Range } \\
\text { (nautical } \\
\text { miles)* }\end{array}$ & 1,280 & 1,100 & 1,158 & 1,160 \\
\hline $\begin{array}{l}\text { Takeoff } \\
\text { distance (feet) }\end{array}$ & 2,155 & 3,400 & 3,120 & 3,400 \\
\hline $\begin{array}{l}\text { Expected retail } \\
\text { price }\end{array}$ & $\$ 1,500,000$ & $\$ 2,250,000$ & $\$ 2,623,000$ & $\$ 2,750,000$ \\
\hline $\begin{array}{l}\text { Expected } \\
\text { service entry } \\
\text { date }\end{array}$ & 2006 & 2007 & 2006 & 2008 \\
\hline
\end{tabular}

Table 1. Operating Characteristics for Selected VLJ Aircraft 
The Small Aircraft Transportation System Program (SATS) [4] led by NASA, demonstrated new operating capabilities that allow higher volume operations at nontowered /non-radar airports and lower landing visibility minima in poor weather at minimally equipped landing facilities. These capabilities make it possible for VLJs to operate reliably at many more airports than those used by commercial and business jets today. The SATS operating capabilities are not essential to VLJ operations and but will enable VLJ operators to reach a wider potential passenger base and be less affected by weather in the future.

The affordable cost relative to existing business jets and the ability to use many of the existing small, minimally equipped, but conveniently located airports are projected to stimulate a large demand for the aircraft.

The economics of operating VLJs are attractive to Air-taxi Operators providing ondemand service mainly for business purposes. For example, DayJet Corporation [5] based in Florida, is starting an on-demand, pay-per-seat, air-taxi-operation in 2007. Other U.S. air-taxi operators planning to use VLJs include Linear Air and Imagine Air.

There is also expected to be significant VLJ demand from corporations, fractional share operations and wealthy individuals. This additional VLJ demand has not been quantified and was therefore not included in this study.

The FAA does not explicitly include VLJ traffic in the Aerospace Forecast, but does increase the General Aviation growth forecast somewhat to take into account the expected introduction of VLJs. The FAA forecast predicts that 6300 VLJs will be in operation by 2020 growing at a rate of 400 to 500 additional per year. Extrapolating beyond 2020 to 2025 using the same growth rate, there would be 8300 to 8500 VLJs operating in 2025.

VLJs are expected to generate significant economic benefits for the U.S. beyond the value of time savings to the users. CRA International [6] concluded that: "Total economic activity in 2017 related to VLJs in some fashion will total nearly \$24 billion in output, $\$ 6.9$ billion in earnings, and over 189,000 jobs.”

From a mobility and economic standpoint there is considerable incentive to ensure that VLJ traffic can be accommodated in the NAS without increasing delays.

\section{Demand Forecasting and Flight Schedule Generation}

An analysis of future concepts for air transportation systems depends on being able to predict future demand and transportation patterns. The demand forecast used for this study includes the growth in commercial passenger, air cargo, general aviation and VLJ air-taxi traffic projected for the year 2025. This demand projection is then used to generate a flight schedule by growing a baseline day of recorded air traffic and adding 
VLJ traffic. The schedule is refined by introducing larger aircraft, increasing load factors and changing the route structure to produce a realistic scenario for 2025.

The baseline schedule for current traffic levels used was ETMS recorded data for $19 \mathrm{Feb}$ 2004 (including international flights to and from the U.S.). This is the day chosen as a typical good weather day for the JPDO Evaluation and Analysis Division (SEAD) baseline traffic day.

Different categories of air traffic do not have the same patterns of growth and are treated separately as discussed below.

\section{Commercial Air Carrier, Scheduled Commuter and Legacy Air-taxi Flights}

The demand forecast for this category of traffic was generated using the Transportation Systems Analysis Model (TSAM). TSAM is under development by Virginia Tech's Air Transportation Systems Lab and NASA Langley [7].

TSAM is a multi-mode, national model that predicts the demand for all long distance travel at a county level based upon population and demographics. The modes of transportation available were scheduled commercial flights, automobile and VLJ air-taxi. TSAM can also consider alternative modes, such as trains or novel modes of transportation such as personal air-vehicles, but only the three modes listed above were modeled for this study.

TSAM conducts a mode choice analysis to compute the demand for each of the three modes of travel based upon the traveler's purpose of the trip, value of time, cost and time of the trip. The county demand for airline travel is then distributed to the airport level, where the enplanements demand at 443 U.S. commercial airports is projected.

It is well recognized that demand for air service has been significantly reduced for short range trips by the time delays and uncertainty associated with enhanced security procedures. A goal of NextGen is to reduce curb-to-curb travel time by an average of $30 \%$. Much of this reduction will be achieved by decreasing airport processing times, with some improvement also gained by reduced taxi times and shorter block times due to more direct routing. This means that short trips will benefit from the largest percentage reduction with longer trips showing a modest percentage reduction in curb-to-curb times.

This reduction in curb-to-curb time is an important factor since this makes shorter commercial flights more attractive to passengers. This diverts some potential demand from automobiles and VLJ aircraft to commercial airlines. Table 2 shows the values that were assumed when generating the commercial demand forecast using TSAM. A reduction of $5 \%$ in gate-to-gate time was also assumed. 


\begin{tabular}{|l|l|l|l|l|}
\hline & \multicolumn{2}{|l|}{$\begin{array}{l}\text { Current } \\
\text { (hrs) }\end{array}$} & Processing Time & \multicolumn{2}{l|}{ Reduced Processing Time (hrs) } \\
\hline & Departure & Arrival & Departure & Arrival \\
\hline Large Hub & 2.0 & 0.75 & 1.0 & 0.5 \\
\hline $\begin{array}{l}\text { Medium } \\
\text { Hub }\end{array}$ & 1.5 & 0.75 & 1.0 & 0.5 \\
\hline Small Hub & 1.25 & & & 0.33 \\
\hline Non Hub & 1.0 & 0.5 & 0.75 & 0.33 \\
\hline
\end{tabular}

Table 2. NextGen Reduced Airport Processing Times

The growth factors determined by TSAM for each of the commercial airports are used as input to the Future Air Traffic Growth and Schedule Model developed by NASA Langley [8]. This code grows a baseline schedule to generate a future schedule. The baseline schedule used was the commercial traffic recorded by ETMS for 19 February 2004.

The number of scheduled flights takes into account an increase in load factor. The average load factor of $76 \%$ in 2004 was increased to $80 \%$ in 2025.

The schedule is then refined by introducing new direct routes between city pairs, when demand warrants (removing connecting flights), based on TSAM passenger trip demand between origin and destination airport pairs.

New direct routes are introduced between airport pairs (where none exist in the 2004 baseline) when passenger demand exceeds 25,000 enplanements annually. This is sufficient to justify 2 flights per day each way in a 50 seat sized aircraft.

The schedule is further refined by substituting larger aircraft for two or more smaller aircraft once schedule frequency between an airport pair is sufficient to meet a satisfactory level of service.

Larger aircraft (along with extra flights) start to be substituted when flight frequency reaches 12 flights per day between a city pair, reducing the number of extra flights needed to meet the passenger demand. The flight frequency is capped at 40 flights per day, or the 2004 frequency if 40 flights per day are exceeded in the 19 Feb 2004 data; see Table 3 below. When this limit is reached only larger aircraft are substituted to meet passenger demand (no additional flights). This is based on research by Airbus; see the Global Market Forecast [9]. 


\begin{tabular}{|l|l|l|l|}
\hline $\begin{array}{l}\text { Departure } \\
\text { Airport }\end{array}$ & $\begin{array}{l}\text { Arrival } \\
\text { Airport }\end{array}$ & $\begin{array}{l}\text { Total } \\
\text { Departures } \\
\text { 19 Feb 2004 }\end{array}$ & $\begin{array}{l}\text { Total } \\
\text { Departures } \\
\mathbf{2 0 2 5}\end{array}$ \\
\hline BOS & LGA & 44 & 44 \\
\hline LGA & DCA & 41 & 41 \\
\hline SAN & LAX & 40 & 40 \\
\hline PDX & SEA & 38 & 39 \\
\hline ORD & MSP & 37 & 39 \\
\hline ATL & DFW & 34 & 37 \\
\hline LAX & LAS & 34 & 37 \\
\hline LGA & ORD & 34 & 35 \\
\hline
\end{tabular}

Table 3. Commercial and Scheduled Commuter/ Air-taxi Daily Flight Frequency for Top City Pairs

The growth in passenger demand from TSAM is projected to be about $2 \mathrm{X}$ system wide by the year 2025 without taking into account the NextGen reduction in curb-to-curb times. This is in agreement with the FAA forecast extrapolated to 2025 for the growth in passenger enplanements. When the NextGen time savings are taken into account the projected demand is increased to about 2.3X system wide with many passengers choosing to travel by commercial air on the shorter trips that are currently taken by automobile.

The number of commercial operations generated by the Growth and Schedule Model to meet the 2.3X growth in passenger trips is $1.86 \mathrm{X}$ the 2004 baseline. The growth in operations is less than the growth in passenger trips due to the combined effects of increased passenger load factors, new direct routes and use of larger aircraft. The number of flights generated is summarized in Table 5 at the end of this section.

The FAA forecast, extrapolated to 2025, predicts a $2 \mathrm{X}$ growth in passenger trips and a $1.56 \mathrm{X}$ increase in operations. The FAA growth in operations is less than that derived from the TSAM demand projection. In general, the demand projected from TSAM and the number of operations generated from the Growth and Schedule Model are not expected to be exactly in line with the FAA forecast. This is because TSAM uses a different methodology and both TSAM and the Growth and Schedule Model may be using different assumptions than those used for the FAA forecast. For this particular study the reduction in curb-to-curb times due to NextGen increases the passenger trip demand. This is an indication of the type of effects that TSAM can predict that cannot be derived from the FAA forecast data. The growth in operations is consequently larger than that derived from FAA data. In addition, the Growth and Schedule Model did not take into account the assumed increase in regional jet size from 48 to 62 seats used in the FAA forecast. 


\section{Cargo Flights}

The cargo air traffic was simply scaled by a fixed factor of $2 \mathrm{X}$, to approximately represent the cargo demand expected in 2025. The cargo traffic is not a significant factor in this study. The number of cargo flights in the 19 Feb 2004 ETMS data is only about $5 \%$ of the total and many cargo flights take place at night, when NAS capacity is not an issue. The number of flights generated is summarized in Table 5.

\section{Legacy General Aviation IFR Flights}

The General Aviation (GA) IFR traffic is not modeled in TSAM and was generated using a GA Operations Model developed by NASA Langley and the Logistics Management Institute. The GA jet traffic is growing rapidly and is forecast to continue to do so, due to the increased use of business jets in the U.S. The overall GA traffic growth is forecast to be nearly $2.5 \mathrm{X}$ the baseline 2004 traffic by 2025 . VFR traffic was not included. The number of flights generated is summarized in Table 5 .

Note: VFR flights can be generated by the GA Operations Model but were not included because the focus of this study is the impact of VLJ air-taxi operations on commercial traffic; these are all IFR flights.

\section{Very Light Jet Air-taxi Flights}

The VLJ air-taxi schedule was generated directly from TSAM. A major issue surrounding VLJ air-taxi operations is the size of the airports that are likely to see VLJ air-taxi operations. Currently, some General Aviation (GA) traffic uses many of the major airports as identified in the FAA's Operational Evolution Plan (OEP). It is possible that some VLJ air-taxi operators may choose to also use OEP airports for some of their operations, unless cost or congestion prevents them from doing so. The study documented in [10] considers this possibility and investigated the effect on delays both with and without VLJ operations at OEP airports. However, it is considered unlikely that significant numbers of VLJ air-taxi operations would take place at OEP airports. The DayJet business model [5] is to offer point-to-point services between smaller airports and not to operate at major airports. For this study, only the case without VLJ air-taxi operations at major OEP airports is considered.

Although VLJs are able to operate at airports that would not accommodate most other conventional passenger aircraft, their use in providing reliable commercial air-taxi service requires basic minimum criteria at airports to be served. 
Candidate airports in the FAA's airport database (March 2006) were screened against the following criteria:

- Public use

- Located in the continental United States

- Paved runway

- Runway length of 3,500 feet or more

- Runway width of 75 feet or more

- Runway edge lights.

Out of more than 20,000 landing facilities in the FAA database, 2,074 facilities meet the above criteria. These were used as an initial set of candidate airports.

Even though the resulting increase in air traffic operations is predicted to be mainly at smaller airports, some of these airports are in metropolitan areas near large hub airports and share airspace and metering fixes with the hub. Significant additional VLJ traffic flows could cause increased delays at some larger airports, even if they do not have any VLJ operations, unless terminal airspace can be re-designed to incorporate the additional traffic. Some preliminary results for this effect are contained in [10].

The number of VLJ operations predicted by TSAM is dependent on the cost of the service and the time-savings compared to other modes of transportation. TSAM generates demand projections for both business and non-business trips. Using a VLJ air-taxi service is generally significantly more expensive than using commercial airline flights; so the majority of the VLJ demand predicted by TSAM is for business purposes where time savings and convenience generally out-weigh the additional cost.

This study used a fixed cost rate of $\$ 1.85$ per passenger mile in year 2000 \$ (this is about \$2.22 in 2007 \$). This rate is based on a cost analysis performed as part of the SATS program, updated to reflect increases in fuel costs. This is in line with DayJet's projected cost to the passenger of between $\$ 1.50$ and $\$ 3.00$ [5]. TSAM uses several other parameters to characterize VLJ trips; the values used for this study are shown in Table 4. 


\begin{tabular}{|l|l|}
\hline Model Version & Version 3.8 - Release - Date: 04/25/2006 \\
\hline Average Party Size Business & 2.13 persons \\
\hline Average Party Size Non-Business & 3.40 persons \\
\hline SATS Plane & VLJ.PTF generic vehicle \\
\hline SATS Plane Maximum Altitude & $400 \mathrm{FL}$ \\
\hline SATS Plane Range & $1100 \mathrm{NM}$ \\
\hline SATS Plane Acceptance Rate & .76 acceptance rates of potential clients \\
\hline SATS Plane Max. Occupancy & 4 passengers \\
\hline SATS Plane Load Factor & .7 fraction of maximum occupancy \\
\hline Annual Utilization (hours) & 1200 hours \\
\hline Annual Operating Days & 300 days \\
\hline Repositioning Flights & 25 percent \\
\hline Stop Over Time (Minutes) & 45 minutes \\
\hline
\end{tabular}

Table 4. TSAM Parameters used for VLJs

Using the above parameters and cost assumptions the projected demand for VLJ air-taxi operations in 2025 from TSAM is about 20,000 flights per day. Figure 2 shows a screen shot of the simulated VLJ air traffic, near a peak time for the traffic density 


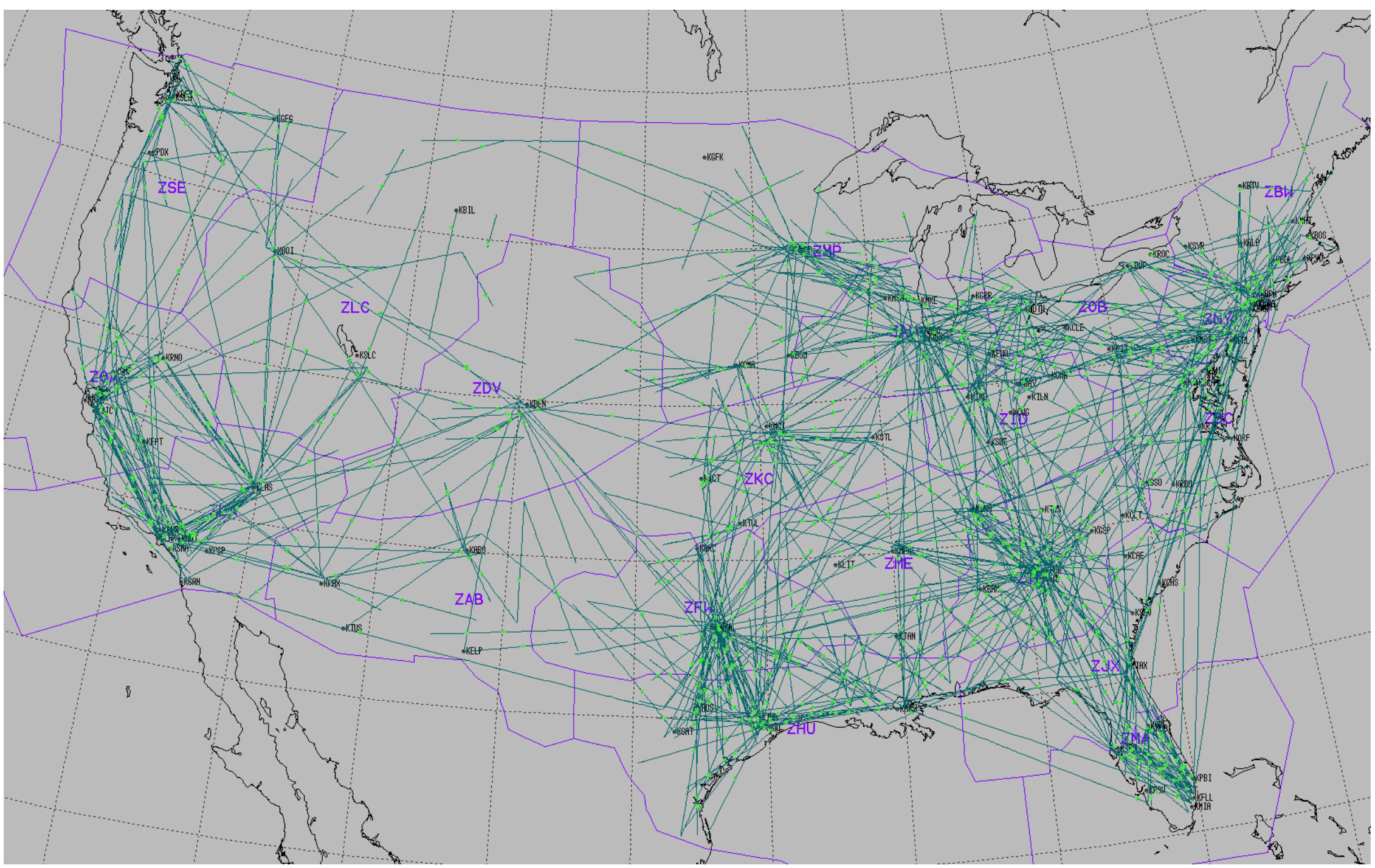

Figure 2. Snapshot of Very Light Jet Air-taxi Operations in the Year 2025 


\section{Combined Air Traffic 2025 Scenario}

Table 5 below lists the various categories of flights and flight numbers used to construct the flight data sets. Table 6 identifies the combined flight data sets used for simulation.

\begin{tabular}{|l|r|l|l|}
\hline & 19 Feb 2004 & $\begin{array}{l}\text { 2025 NextGen } \\
\text { (reduced } \\
\text { commercial } \\
\text { airport processing } \\
\text { times - 5\% gate- } \\
\text { to- gate) }\end{array}$ & $\begin{array}{l}\text { Growth } \\
\text { Factor }\end{array}$ \\
\hline $\begin{array}{l}\text { Commercial/ } \\
\text { Scheduled Commuter } \\
\text { Air-taxi }\end{array}$ & 34,471 & & 1.86 \\
\hline Cargo & 2,323 & 64,059 & 1.98 \\
\hline GA & 12,367 & 4,607 & 2.46 \\
\hline VLJ & N/A & 30,397 & N/A \\
\hline
\end{tabular}

Table 5. Number of Flights in Flight Data Sets by Category

\begin{tabular}{|l|r|r|}
\hline Flight Data Set & Total Flights & $\begin{array}{l}\text { Multiple of } \\
\text { 19 Feb 2004 }\end{array}$ \\
\hline 19 Feb 2004 Baseline Day & 49,961 & N/A \\
\hline 2025 & 99,063 & 1.98 \\
\hline $\mathbf{2 0 2 5}+$ VLJ & 118,981 & 2.38 \\
\hline
\end{tabular}

Table 6. Flight Data Sets used for Analysis

\section{Distance Distribution of Air Traffic}

The distance distribution of passenger trips is important because for shorter trips it is not efficient to climb to high altitudes, due to the time taken to climb and descend. The trip length of VLJ air-taxi operations will determine the maximum altitude of flights and this effects how much interaction VLJs have with commercial aircraft during the en-route stage of the flight. All distances in this section are the great circle distance, which is the shortest distance between the origin and destination airports and not actual distance flown. Table 7 summarizes the data and the following sections provide a more detailed explanation of the differences between categories of air traffic. 


\begin{tabular}{|c|c|c|c|c|c|c|c|}
\hline \multirow{2}{*}{$\begin{array}{l}\text { Flight } \\
\text { Data } \\
\text { Set }\end{array}$} & \multirow[t]{2}{*}{$\begin{array}{l}\text { Aircraft } \\
\text { Type }\end{array}$} & \multicolumn{3}{|c|}{$\begin{array}{l}\text { Mean Flight Leg Great } \\
\text { Circle Distance (nm) }\end{array}$} & \multicolumn{3}{|c|}{$\begin{array}{l}\text { Mean Cruise Altitude } \\
\text { (ft) }\end{array}$} \\
\hline & & Commercial & GA & VLJ & Commercial & GA & VLJ \\
\hline \multirow{2}{*}{$\begin{array}{l}19 \text { Feb } \\
2004\end{array}$} & All & 608 & 331 & & 26,400 & 18,100 & \\
\hline & Jet & 736 & 500 & & 30,500 & 29,400 & \\
\hline \multirow[t]{2}{*}{2025} & All & 646 & 443 & & 26,200 & 24,000 & \\
\hline & Jet & 760 & 531 & 213 & 31,000 & 32,400 & 23,600 \\
\hline
\end{tabular}

Table 7. Flight Leg Distance and Cruise Altitude for Categories of Air Traffic

\section{Commercial, Scheduled Commuter and Air-taxi}

The distance distribution of commercial and scheduled commuter/ air-taxi flights taken directly from the ACES flight data set generated from ETMS recorded data for 19 Feb 2004 is shown in Figure 3. The average distance of all aircraft is $608 \mathrm{~nm}$ and the average cruise altitude is $26,400 \mathrm{ft}$. The average distance of jet only traffic is longer at $736 \mathrm{~nm}$ and the average cruise altitude is higher at 30,500 ft; see Figure 4.

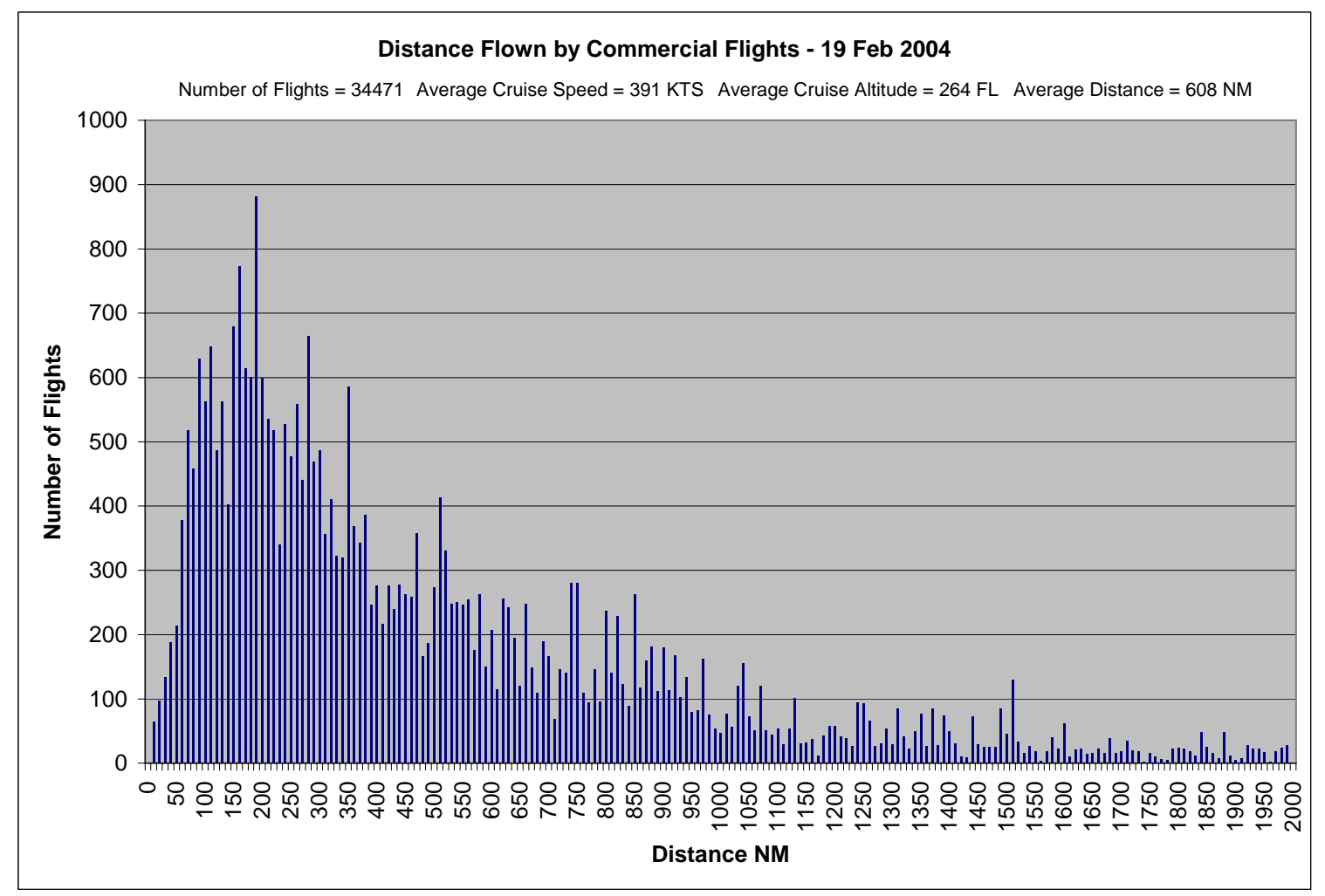

Figure 3. Distances Flown by All Commercial Flights in 19 Feb 2004 ETMS Data 


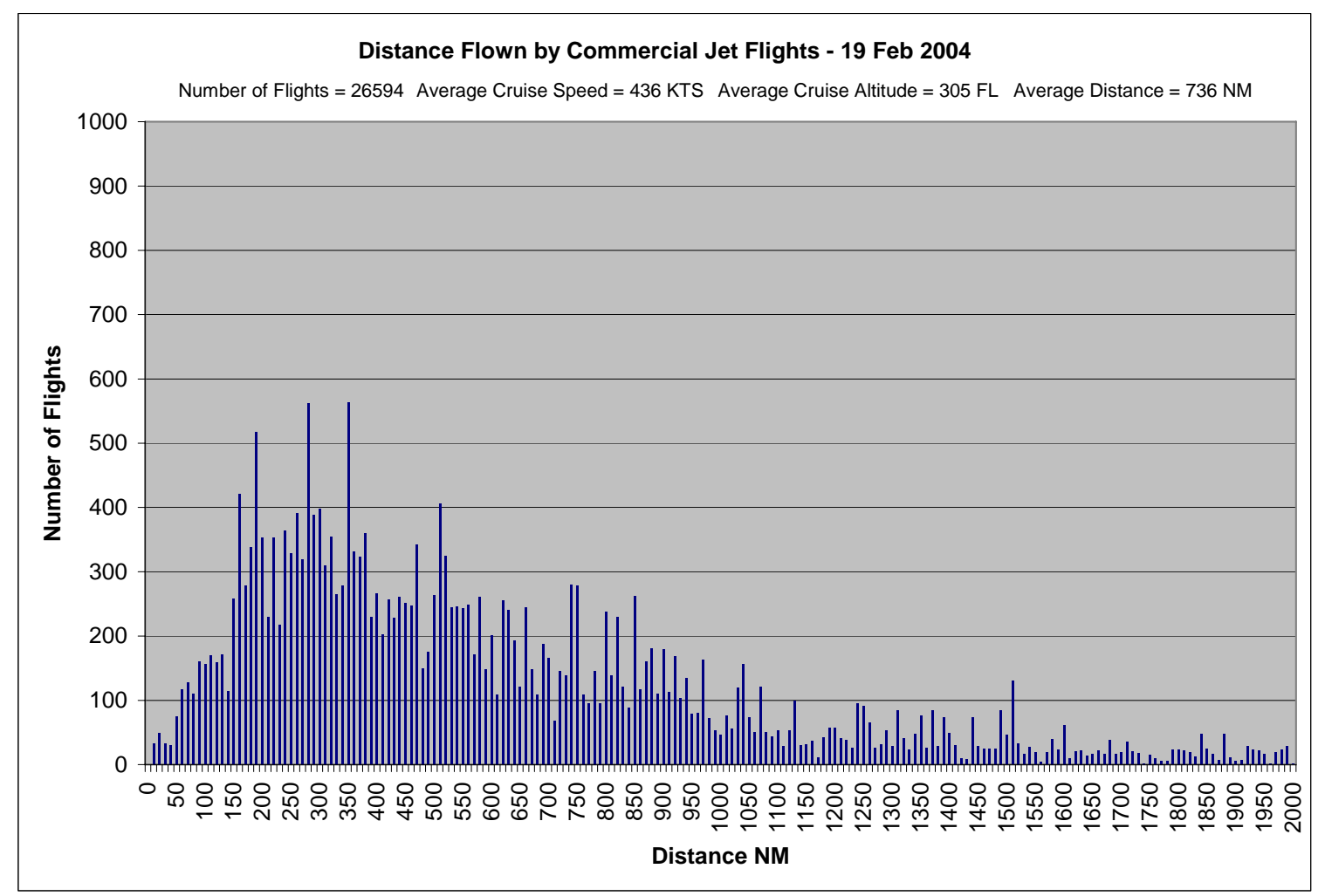

Figure 4. Distances Flown by Jet Commercial Flights in 19 Feb 2004 ETMS Data

The 2025 flight data set has a somewhat longer flight average distance of $646 \mathrm{~nm}$ for all traffic and $760 \mathrm{~nm}$ for jets, due to the introduction of longer direct routes replacing shorter connecting legs. This change in flight segment distance is not sufficient to significantly effect the altitude distribution; the average cruise altitude is 26,200 ft for all traffic and 31,000 ft for jets.

\section{General Aviation IFR Flights}

The distance distribution of general aviation flights taken directly from the ACES flight data set generated from ETMS recorded data for 19 Feb 2004 is shown in Figure 5. The average distance is $331 \mathrm{~nm}$ with an average cruise altitude of 18,100 ft. The average distance of jet only GA traffic is longer at $500 \mathrm{~nm}$ with an average cruise altitude that is higher at 29,400 ft; see Figure 6.

The 2025 GA flight data has an average distance for all flights of $433 \mathrm{~nm}$ and an increased average cruise altitude of 24, $000 \mathrm{ft}$. The average distance of 2025 jet only GA traffic is $531 \mathrm{~nm}$ with an average cruise altitude of 32,400 ft.

The 2025 GA average distance including all flights is significantly longer than the 19 Feb 2004 average distance. This is explained by the differential growth rates of GA jet traffic compared to non-jet traffic. In the 19 Feb 2004 data there are 4942 jet flights out of a total of 12,367 flights; jets are $40 \%$ of the total. For the 2025 demand GA jet traffic is 
forecast to grow much faster than the non-jet traffic. In the 2025 demand there are 17,669 jet flights out of a total of 30,397 flights; jets are now 58\% of the total. Since jets fly longer distances and higher altitudes than non-jets on average, this explains the increases noted.

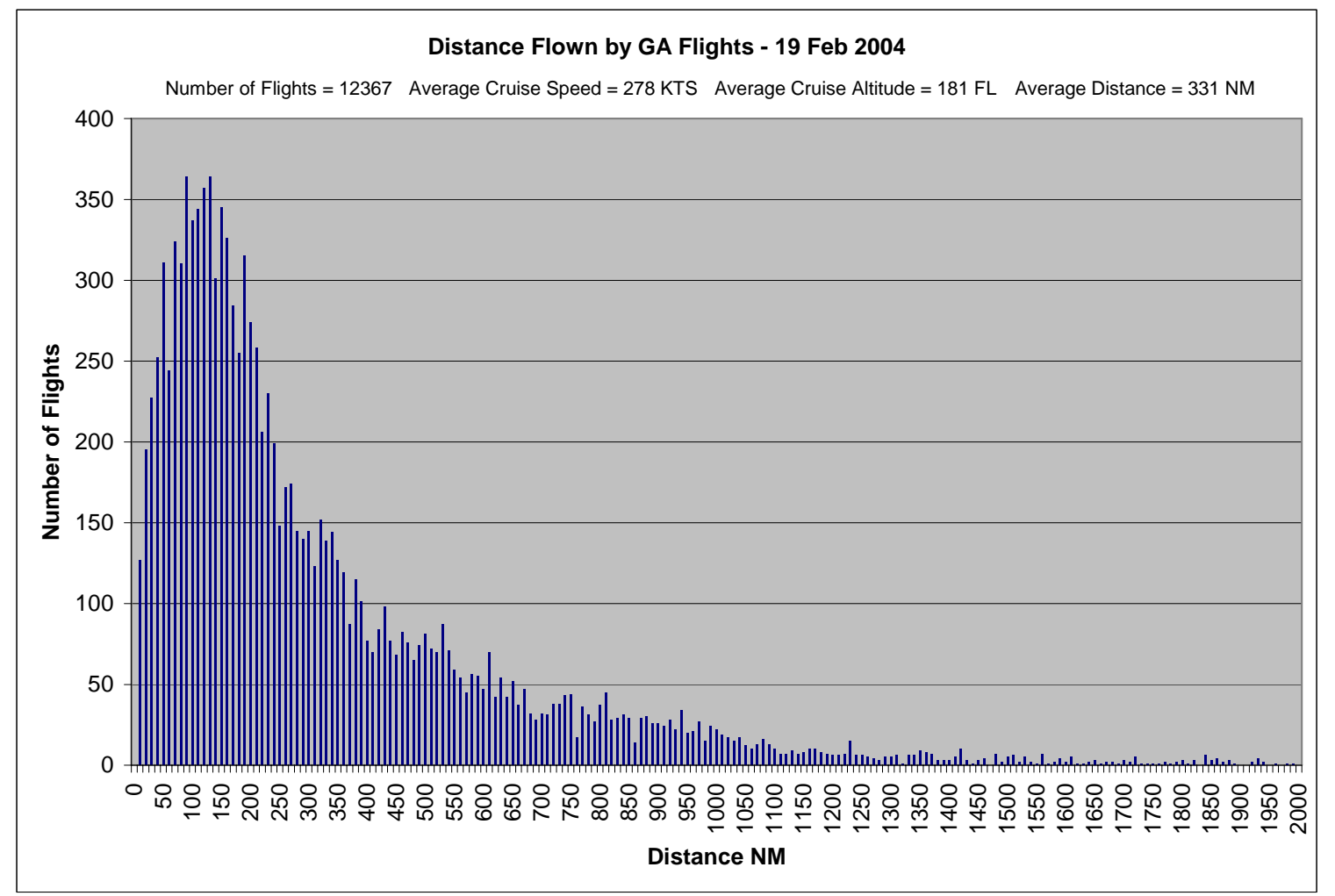

Figure 5. Distances Flown by GA Flights in 19 Feb 2004 ETMS Data 


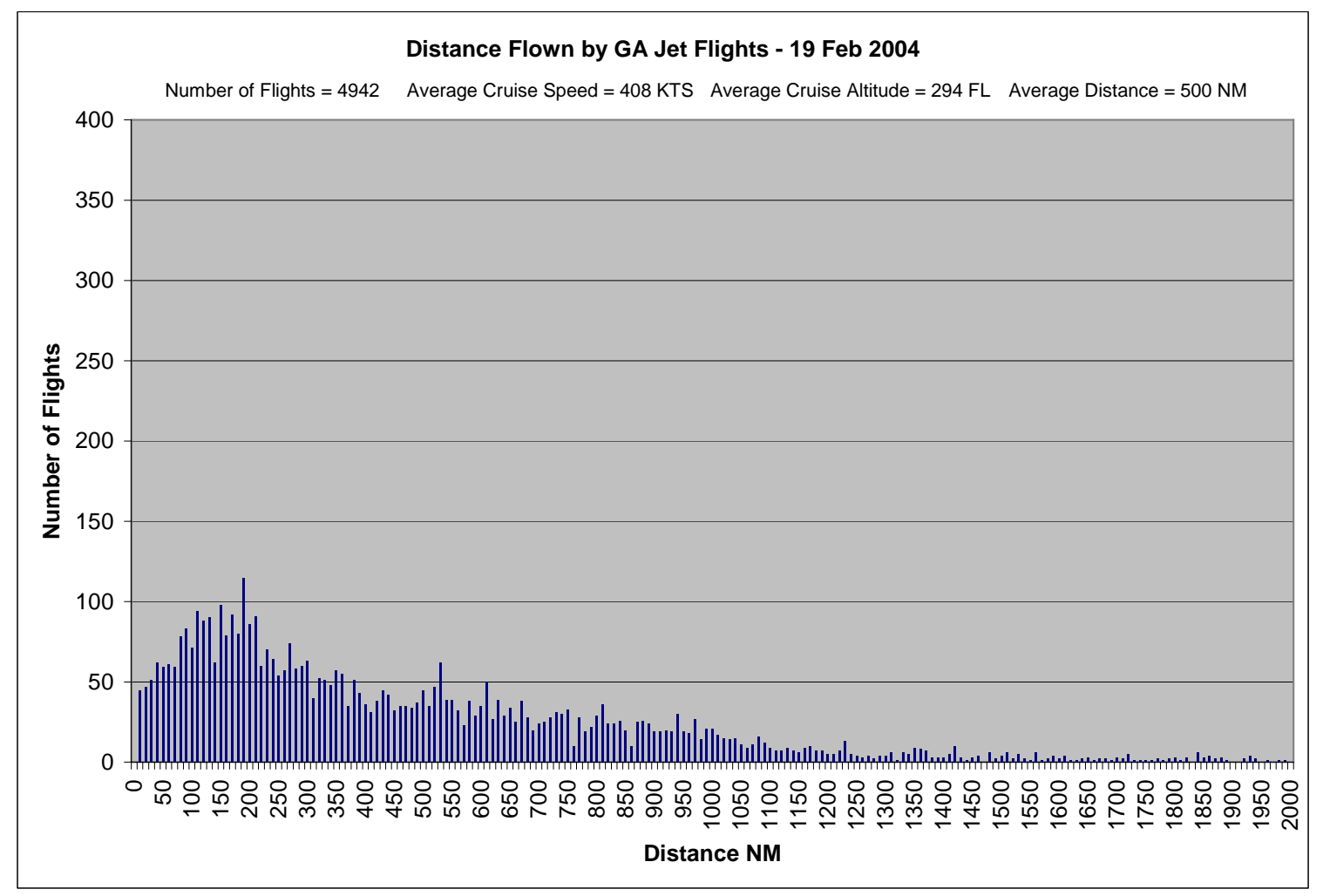

Figure 6. Distances Flown by Jet GA Flights in 19 Feb 2004 Flight ETMS Data

\section{Very Light Jets Air-taxi Operations}

The distance distribution for VLJ flights in the 2025 flight data set is shown in Figure 7. The average flight leg distance is quite short at $213 \mathrm{~nm}$; the average cruise altitude is 23,600 ft. The relatively short average distance of VLJ flights indicates that the primary market for VLJ air-taxi operators is the passenger trips currently being taken mainly by automobile.

The VLJ distance distribution is very different to the flight pattern of the GA business jets in the 19 Feb 2004 data; compare Figure 7 to Figure 6. The GA business jets fly much further and higher on average. Some GA business jets fly distances of $2000 \mathrm{~nm}$ or more whereas VLJ traffic does not extend beyond $1000 \mathrm{~nm}$ due to the range limits of VLJ aircraft before a re-fuelling stop is required. When a refueling stop is included the time advantage of VLJs is lost compared to commercial air transportation, so there is very little demand for air-taxi flights that require a fuel stop.

This usage pattern by VLJs for relatively short trips is driven by two factors:

- For trips of less than about 120 statute miles driving distance, it does not save much time and it costs significantly more to use a VLJ compared to using a car; 
- For trips longer than about $600 \mathrm{~nm}$ to $700 \mathrm{~nm}$ VLJs start to get expensive compared to commercial airline fares and the proportional time savings are not as great as for medium distance trips. VLJs are slower than commercial jets so the time advantage is less for longer range trips. For trips over $1000 \mathrm{~nm}$ a fuelling stop is required which reduces or eliminates any time advantage over commercial flights.

The shorter distances flown by VLJs mean that many flights will be below the altitudes used by commercial airlines, in less congested airspace.

Note that the flight distances are in Nautical Miles and are Great Circle (direct) distances. Driving distances will be significantly longer than the Great Circle distance. The average one-way $213 \mathrm{~nm}$ flight distance (245 statute miles) would generally take at least 280 to 300 statute miles to drive or perhaps 5 to 6 hours each way of driving time.

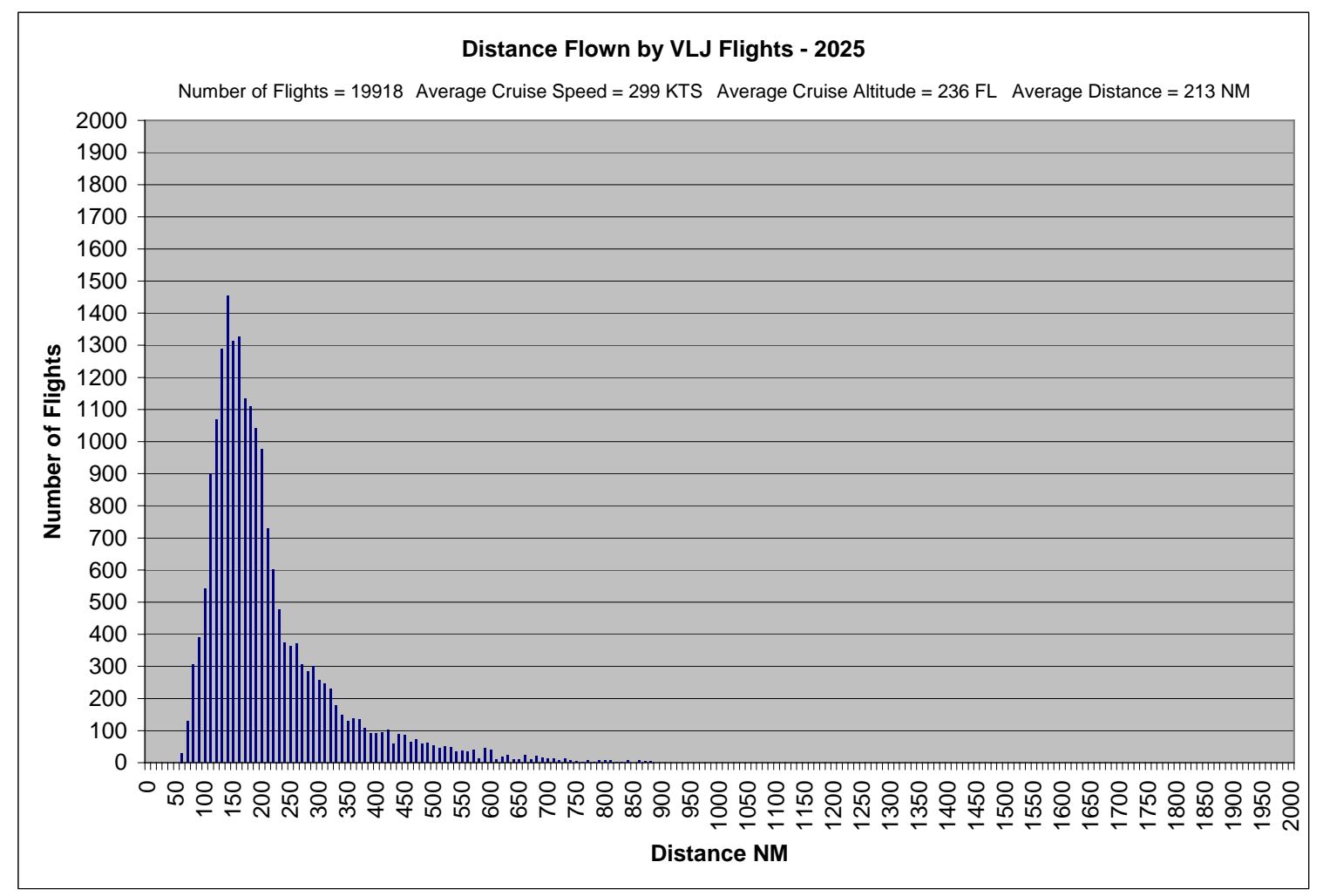

Figure 7. Distances Flown by VLJ Flights in 2025 Flight Data Set

\section{Capacity Enhancing Concepts}

One of the key elements of the NextGen concept is Trajectory Based Operations (TBO). Flights are managed through use of four-dimension trajectories (4DT) that specify accurate current and future aircraft position. Spaced-based navigation and co-operative surveillance provides accurate aircraft position and intent. Use of TBO allows significant 
automation of the separation management function, using ground based and flight deck based systems.

In en-route airspace, the current system capacity is primarily limited by the capability of a team of air traffic controllers to handle traffic. U.S. airspace is divided into sectors with a capacity of between about 12 to 23 aircraft depending on sector size and traffic complexity. Use of automation with increased aircraft position accuracy and knowledge of future intent is expected to allow for a significant increase in airspace capacity.

The increase in airspace capacity that could be achieved by NextGen is the subject of current research. The JPDO Systems and Engineering Analysis Division (SEAD) expectations for the capabilities of the NextGen have been stated as a factor of $3 \mathrm{X}$ increase in sector capacity. However, this is subject to significant uncertainty, so this study uses a range of sector capacities from $1.3 \mathrm{X}$ current capacity to $3 \mathrm{X}$ capacity and investigates the effects on delays for the projected demand in 2025.

Airport capacity must also be increased to take advantage in any increase in airspace capacity. The JPDO SEAD expectations for the capabilities of the NextGen have been stated as a factor of $1.4 \mathrm{X}$ increase in airport capacity, over and above that already in the FAA OEP for the top 36 U.S. airports. The future airport capacity that might be achieved is also uncertain and is the subject of current research. The focus of this paper is airspace capacity, so OEP airports capacity was increased to 1.4X the OEP Version 5 capacities [11], this being the version of the OEP current in 2004, that is the baseline demand year. The capacity of airports that are not in the OEP was also increased by 1.4X.

\section{The Airspace Concepts Evaluation System}

The simulation program used for this study is the Airspace Concepts Evaluation System (ACES) simulator (build 4.2) which was developed as part of the NASA Virtual Airspace Modeling and Simulation Project led by Ames Research Center. ACES is a comprehensive air transportation systems simulator that includes aircraft models, airport models, airspace boundaries, traffic flow management, airline operations centers, conflict detection and resolution and a trajectory propagator.

ACES contains aircraft flight models for various types of aircraft, including a business jet model representative of a VLJ, and models many components of the NAS, including airports and airspace sectors. For a detailed description of ACES capabilities; see [12].

The OEP airport capacities are increased by $1.4 \mathrm{X}$ over and above the FAA's OEP version 5 capacities; non-OEP airport capacities are also increased by $1.4 \mathrm{X}$.

Sector capacities are increased by 1.3X, 1.5X, 2.0X, 2.5X and 3.0X from 2004 values for the year 2025 analysis. 
For this study the sector boundaries remain as they were in 2004. This does not represent the NextGen view of the airspace in 2025. The JPDO CONOPS envisages using dynamic airspace configuration that changes to meet demand at intervals throughout the day. However, using existing boundaries is useful - it enables projected traffic densities in 2025 to be easily compared to the baseline 2004 traffic densities.

This study does not investigate how airspace capacity may be increased. The scope is limited to determining how much additional capacity might be needed and whether VLJ traffic could significantly add to airspace congestion.

All results presented in this paper assume perfect weather, with all airports operating under Visual Meteorological Conditions and all airspace sectors operating at maximum capacity.

\section{Results}

\section{Flight Delays Analysis}

ACES computed delays are based on an unimpeded flight through the NAS and do not include schedule padding. Airlines typically add a certain amount of time to their flight schedule, because they value predictability above advertising the minimum possible flight time.

ACES simulation results give a realistic estimate of likely delay, but this should not be directly compared to reported delays, which are understated due to schedule padding. In addition airlines do not count flights as delayed for reporting purposes, until the delay is greater than 15 minutes in accordance to the FAA definition of a delayed flight. (Actual flights delays less than 15 minutes are recorded in the FAA databases and can be obtained, but still include schedule padding.)

Figure 8 summarizes the results from ACES simulation for commercial flights. Commercial flights are Air Carrier, Scheduled Commuter and Legacy Air-taxi Flights.

The baseline 19 February 2004 delays average 514 seconds per flight using the 2004 sector capacities and airport capacities.

Using the 2025 flight schedule, the mean delay using a sector capacity multiplier of $1.3 \mathrm{X}$ is 1875 seconds without VLJs and increases to 2143 seconds with VLJs. This increase of 268 seconds per flight shows that VLJ traffic is having a significant effect on commercial flights, but overall the delay with or without VLJs is very high, indicating that the sector capacity is insufficient for the level of traffic projected for 2025.

The chart indicates that about 2.3X to $2.5 \mathrm{X}$ sector capacities is required to keep mean delays with the 2025 demand similar to the 2004 baseline delay. The additional mean delay to commercial traffic due to VLJs is then negligible. The 90th percentiles are also 
shown on the chart. With 2.5X sector capacity 90 percent of flights have delays of less than 840 seconds. Even with $2.5 \mathrm{X}$ sector capacity, mean delay is 566 seconds; that is 52 seconds more than the baseline. This is due to airport capacity limitations.

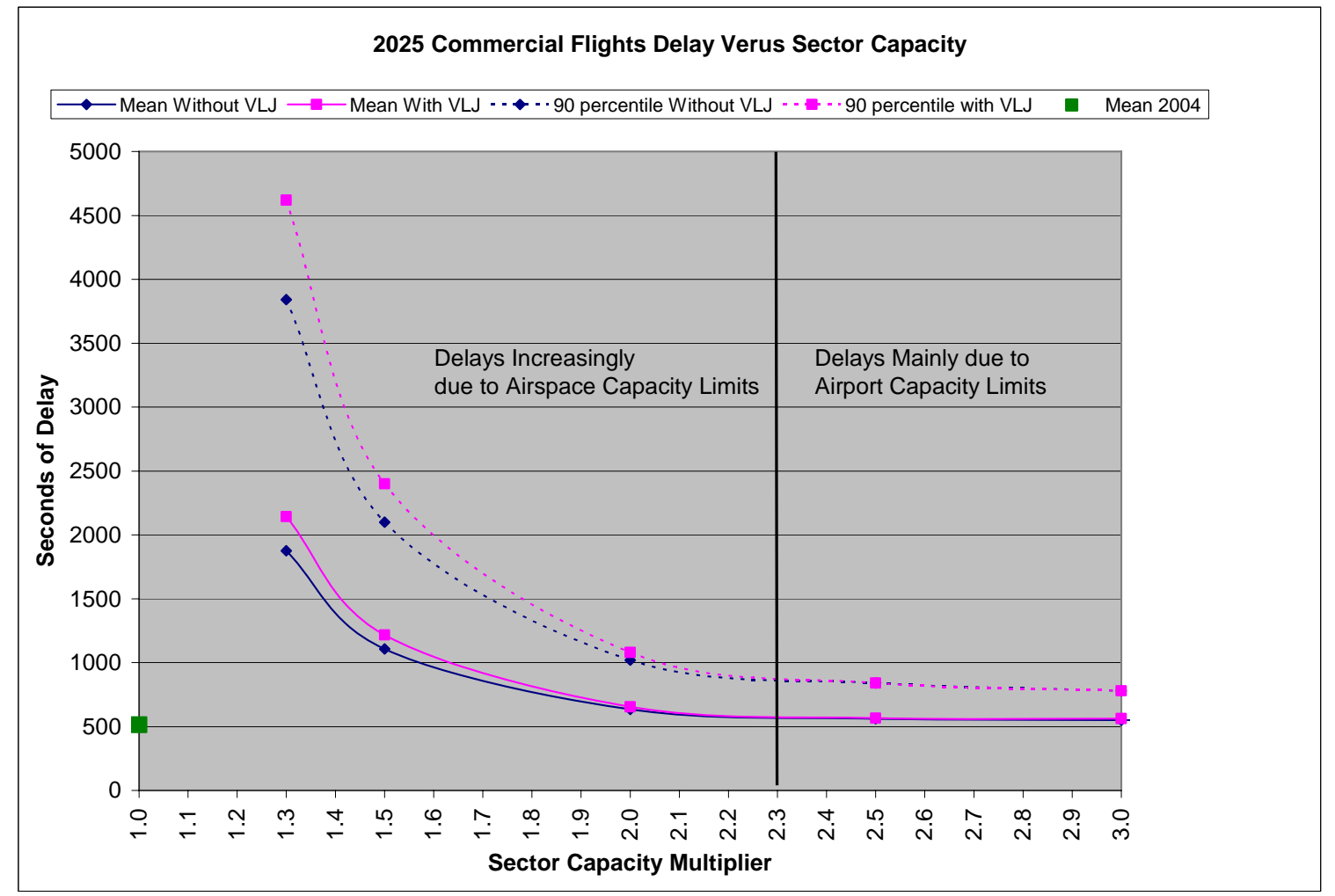

Figure 8 Commercial Flights Delays versus Sector Capacity

\section{Airspace Sectors Load Analysis}

For this analysis the maximum number of flights in a sector, sustained over a 5 minute interval is the metric analyzed as peak load, since this is in line with the FAA facility use of Monitor Alert Parameter (MAP) values. The actual technique used to determine this value was to count the number of aircraft in each sector for each minute of simulation and compute a 5 minute moving average from each minute count.

MAP values are not used directly by sector controllers; they are used by TFM to ensure that as far as possible a sector does not become significantly overloaded. Sector controllers will use their own judgment as to when to start refusing handoffs, request assistance or use other techniques to ensure that they can handle the traffic. They may handle more aircraft than the MAP value suggests for short periods.

Note the following from FAA Order 7210.3U Facility Operation and Administration see http://www.faa.gov/ATpubs/fac/Ch17/s1707.html 
"The Monitor Alert Parameter (MAP) establishes a numerical trigger value to provide notification to facility personnel, through the MA function of the ETMS, that sector/airport efficiency may be degraded during specific periods of time."

"The ability of a functional position or airport to provide air traffic services may be affected by a variety of factors (i.e., NAVACase IDs, meteorological conditions, communications capabilities, etc.); therefore MAP is a dynamic value which will be adjusted to reflect the capabilities of the functional position or airport."

"Baseline MAP values may be adjusted ${ }^{+} / .3$."

"TM initiatives should be primarily for those time frames when the MAP value will be equaled or exceeded for a sustained period of time (usually greater than 5 minutes)."

ACES has a Traffic Flow Management (TFM) algorithm that attempts to keep sector load within sector capacity. This algorithm attempts to keep the traffic load averaged over a 15 minute interval below the MAP value, so short term peaks can occur over the nominal capacity. This is in line with operational practice. Sector overload results in traffic being delayed.

The ACES MAP values are not dynamic (they can be changed by scripting, but this feature was not used for this analysis) and may not be the actual values used on the 19 Feb 2004 baseline day at any specific time of day.

For the above reasons MAP values should not be taken as absolute, exceeding the MAP value by a few flights at peak times is not significant for this analysis.

\section{Feb 2004 Baseline Day Sector Load}

The peak number of flights in the top 50 most heavily loaded sectors for the 2004 baseline demand day is shown in Figure 9, compared to the current MAP value. The peak load exceeds the MAP value by up to 4 flights for several of the sectors and is at or slightly below the MAP value for the rest of the top 50 most heavily loaded sectors. This indicates that the most heavily loaded sectors are at full capacity in today's NAS at peak times and would not be able to accommodate any increase in load. This is not unexpected since it would be wasteful of controller resources to design sectors with significant excess capacity.

ACES categorizes sectors as low, high and super-high. Low sectors generally have an altitude ceiling of 23,900 ft; high are from 24,000 ft to 34,900 ft and super-high are above $35,000 \mathrm{ft}$. However, there are many exceptions; several super-high sectors start at 24,000 $\mathrm{ft}$. and several high sectors start below 13,000 ft.

The most heavily loaded sectors are mainly high sectors; low sectors are not congested. The most heavily loaded sector for this analysis of 19 Feb 2004 is ZAU76. This is a high 
altitude Chicago sector that transitions ORD westbound departures climbing to altitude and works a large volume of over-flight traffic. Figure 10 shows the location of the top 50 most heavily loaded sectors.

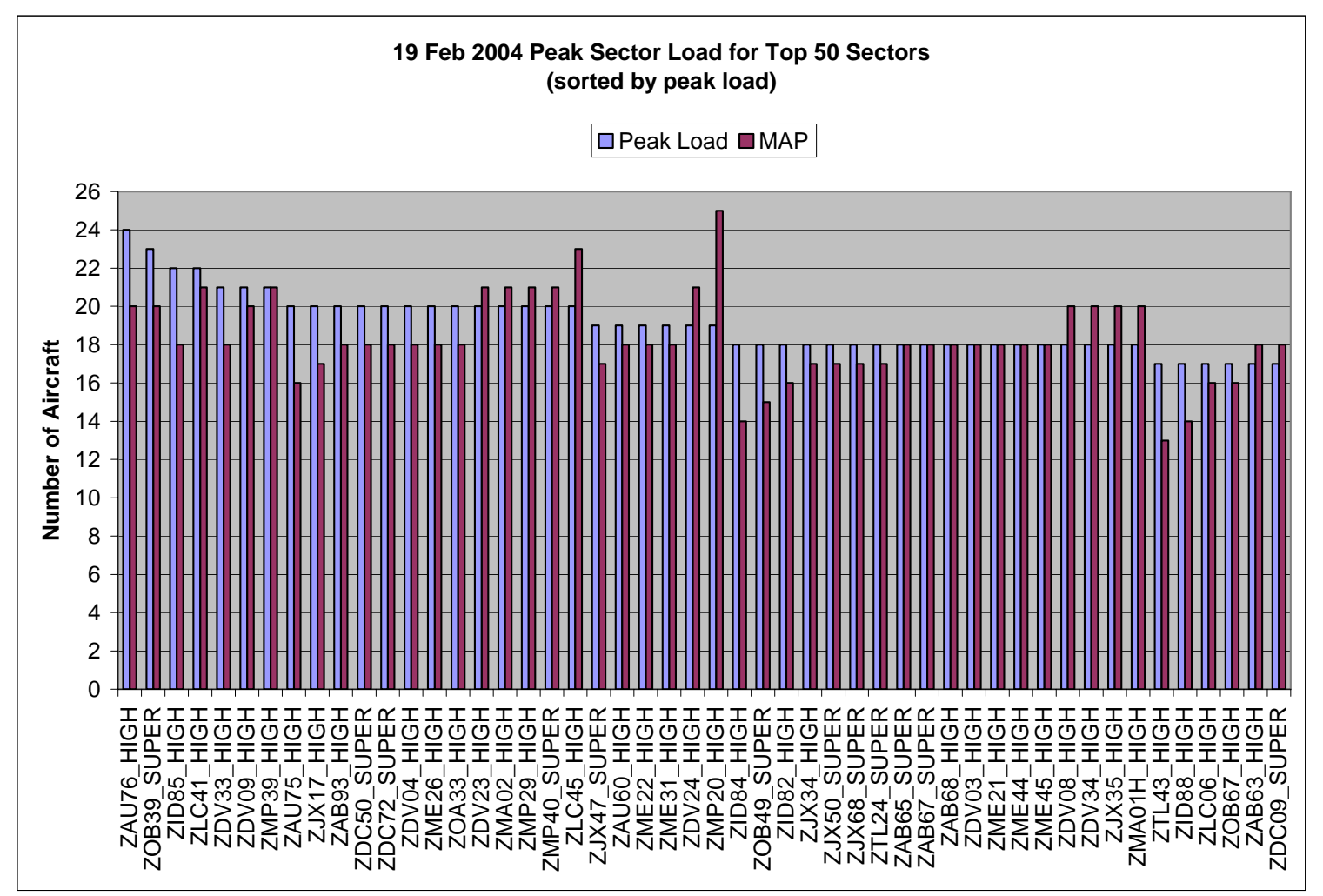

Figure 9. 19 Feb 2004 Peak Sector Load for Top 50 Sectors 


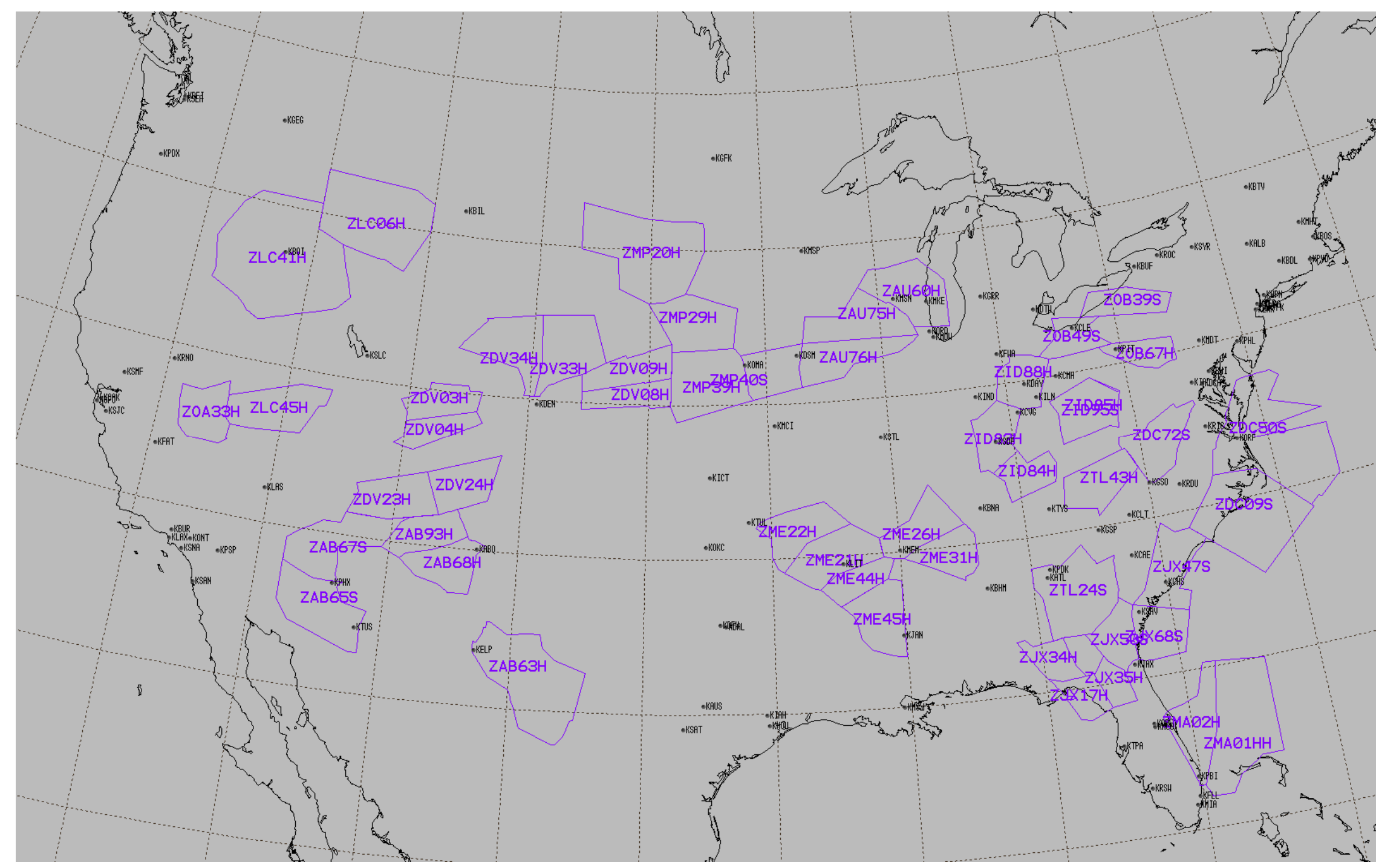

Figure 10. Top 50 Sectors for 19 February 2004 


\section{Sector Load}

The peak number of flights in the top 50 most heavily loaded sectors for the 2025 demand day is shown in Figure 11, compared to the 2.5X sector capacity MAP value. Delay analysis determined that $2.5 \mathrm{X}$ sector capacity was sufficient to meet the demand; see Figure 8. The peak load exceeds the MAP value by 7 flights for ZAU_76 and exceeds the MAP value slightly for a few other sectors. The peak load is at or slightly below the MAP value for most of the top 50 most heavily loaded sectors.

The most heavily loaded sectors are again mainly high sectors, as was the case for the 2004 baseline, low sectors are not congested. The most heavily loaded sector for this analysis is ZAU76, the same Chicago sector that was the most heavily loaded in the 19 February 2004 data.

Figure 12 shows the traffic type present in the same top 50 sectors at the time of peak load, split by non-VLJ and VLJ. For the busiest NAS sectors VLJ air-taxi flights add very little traffic. This is because the average cruise altitude for VLJ traffic is 23,600 ft, somewhat below that of the busiest high altitude sectors. Figure 13 shows the location of the top 50 most heavily loaded sectors.

Table 8 shows the number of en-route sectors that did not have sufficient capacity for the 2025 demand as a function of the capacity multiplier used. Note that ACES recorded traffic counts for 705 en-route sectors. There are many more sectors than this in the NAS. ACES does not model all of the sectors within the NAS; for example sectors within TRACONS are not modeled. Delay analysis of simulation results indicated that $2.5 \mathrm{X}$ sector capacity is sufficient for the 2025 demand. This is confirmed by sector load analysis, since only $1 \%$ of the sectors analyzed were at or slightly above capacity. The simulation results show that $45 \%$ of the current NAS sectors need some increase in capacity; only $19 \%$ of sectors need more than $1.5 \mathrm{X}$ current capacity to meet the projected 2025 total demand that includes VLJ air-taxi flights.

\begin{tabular}{|l|l|r|r|}
\hline Capacity Multiplier & $\mathbf{1 x}$ & $\mathbf{1 . 5 X}$ & $\mathbf{2 . 5 X}$ \\
\hline $\begin{array}{l}\text { Number of Sectors }>= \\
\text { MAP }\end{array}$ & 320 & 136 & 8 \\
\hline $\begin{array}{l}\text { Percentage of Total } \\
\text { (705) En-route Sectors } \\
>=\text { MAP }\end{array}$ & & & \\
\hline
\end{tabular}

Table 8. Number of Sectors at or Exceeding Capacity in 2025 as a function of Sector Capacity Multiplier 


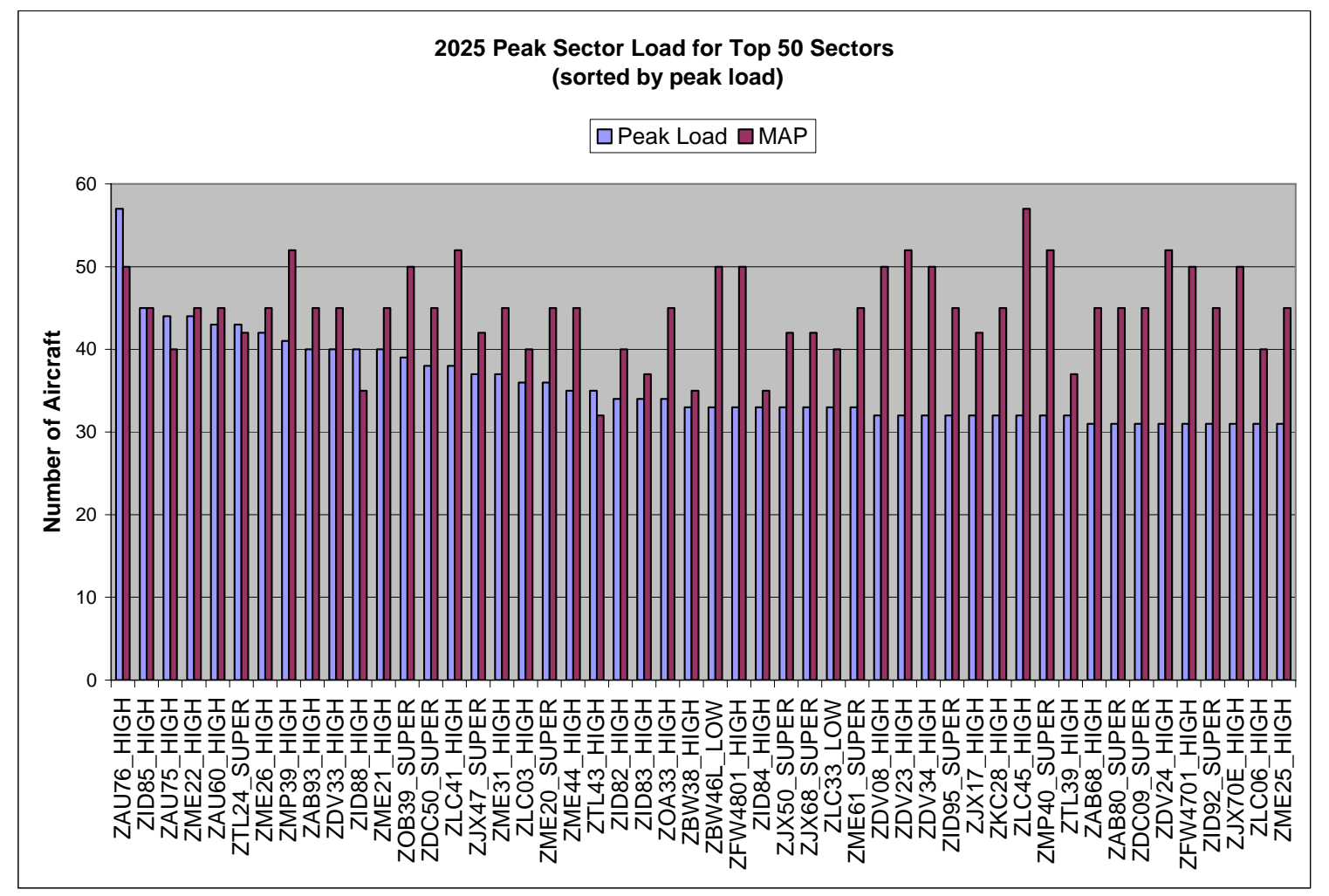

Figure 11. 2025 Peak Sector Load for Top 50 Sectors (2.5X Sector Capacity)

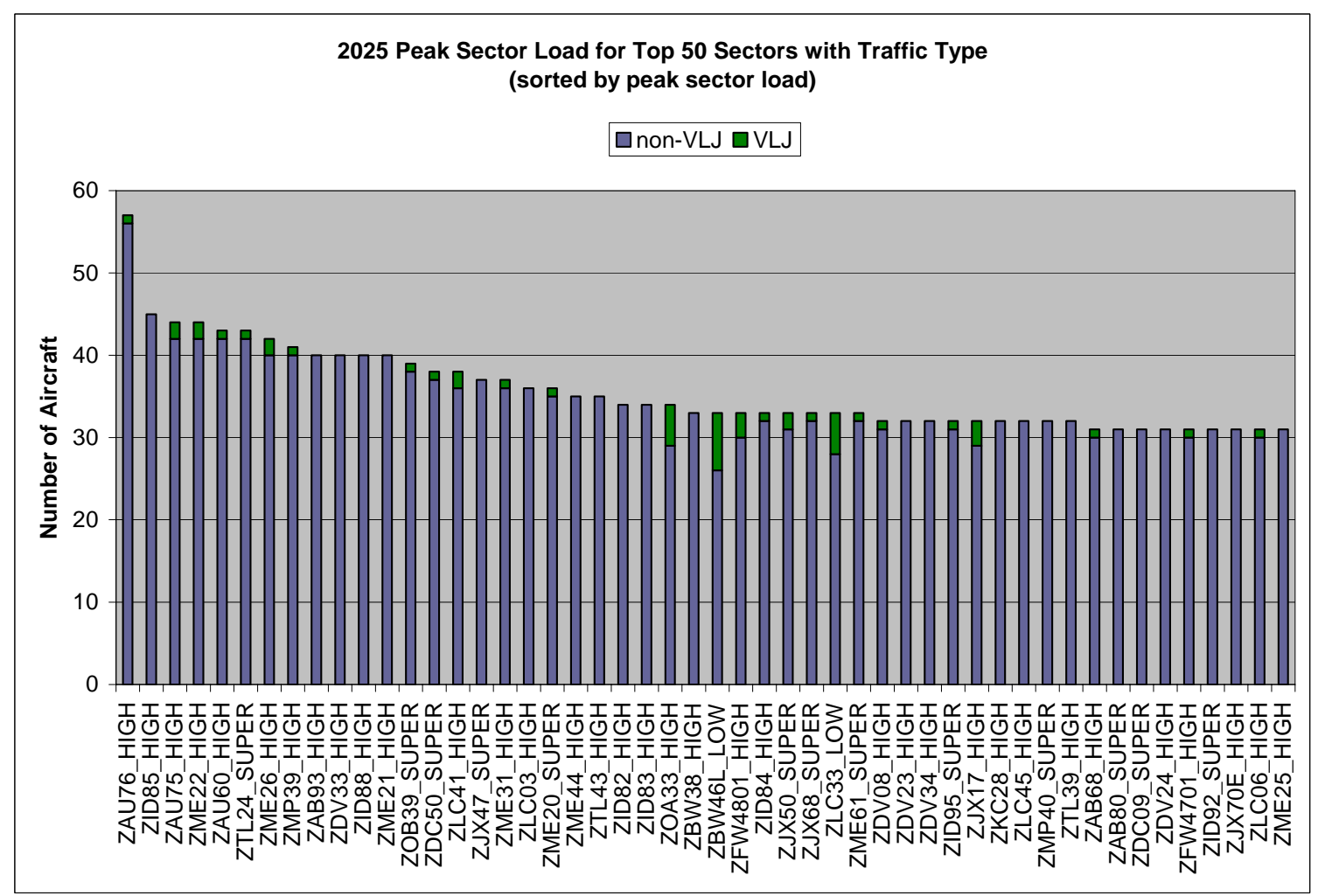

Figure 12. 2025 Peak Sector Load for Top 50 Sectors with Traffic Type 


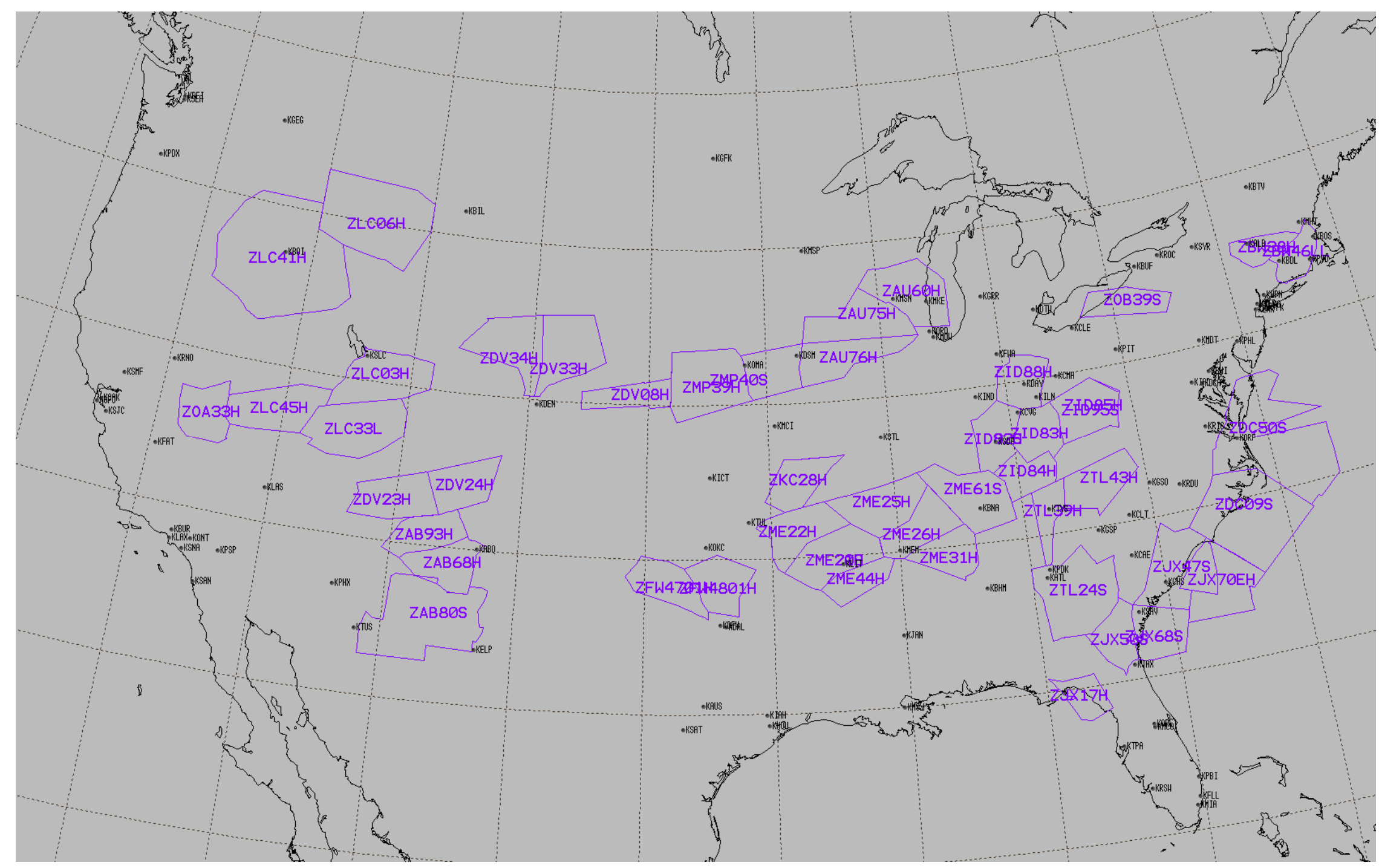

Figure 13. Top 50 Sectors for all 2025 traffic 
The 2025 sector load was also analyzed to determine which sectors had the most VLJ traffic. Figure 14 shows the top 50 sectors with the highest peak VLJ traffic load. Of these, 28 were low sectors and 22 were high sectors. Eight of the high sectors actually had a lower altitude bound of 13,000 ft or less; they are classified as high because the upper bounds are above 34,900 ft. This compares to 48 out of 50 of the busiest sectors overall, with all traffic, being high or super-high sectors - compare Figure 14 with Figure 11. The MAP value is never exceeded, indicating that the busiest sectors for VLJ air-taxi flights have plenty of capacity to meet the demand, assuming a $2.5 \mathrm{X}$ increase in sector capacity is achieved by NextGen.

Figure 15 shows the traffic type present in the same top $50 \mathrm{VLJ}$ sectors at the time of peak load, split by non-VLJ and VLJ. The busiest VLJ sector determined from simulation was ZMA47 low, with $14 \mathrm{VLJ}$ aircraft at the peak of demand. Traffic in this sector is the responsibility of Miami Air Route Traffic Control Center. Figure 16 shows the location of the top 50 heavily loaded sectors by VLJs. ZMA47 is the sector on the Florida peninsula, about $100 \mathrm{~nm}$ North West of Miami airport. 


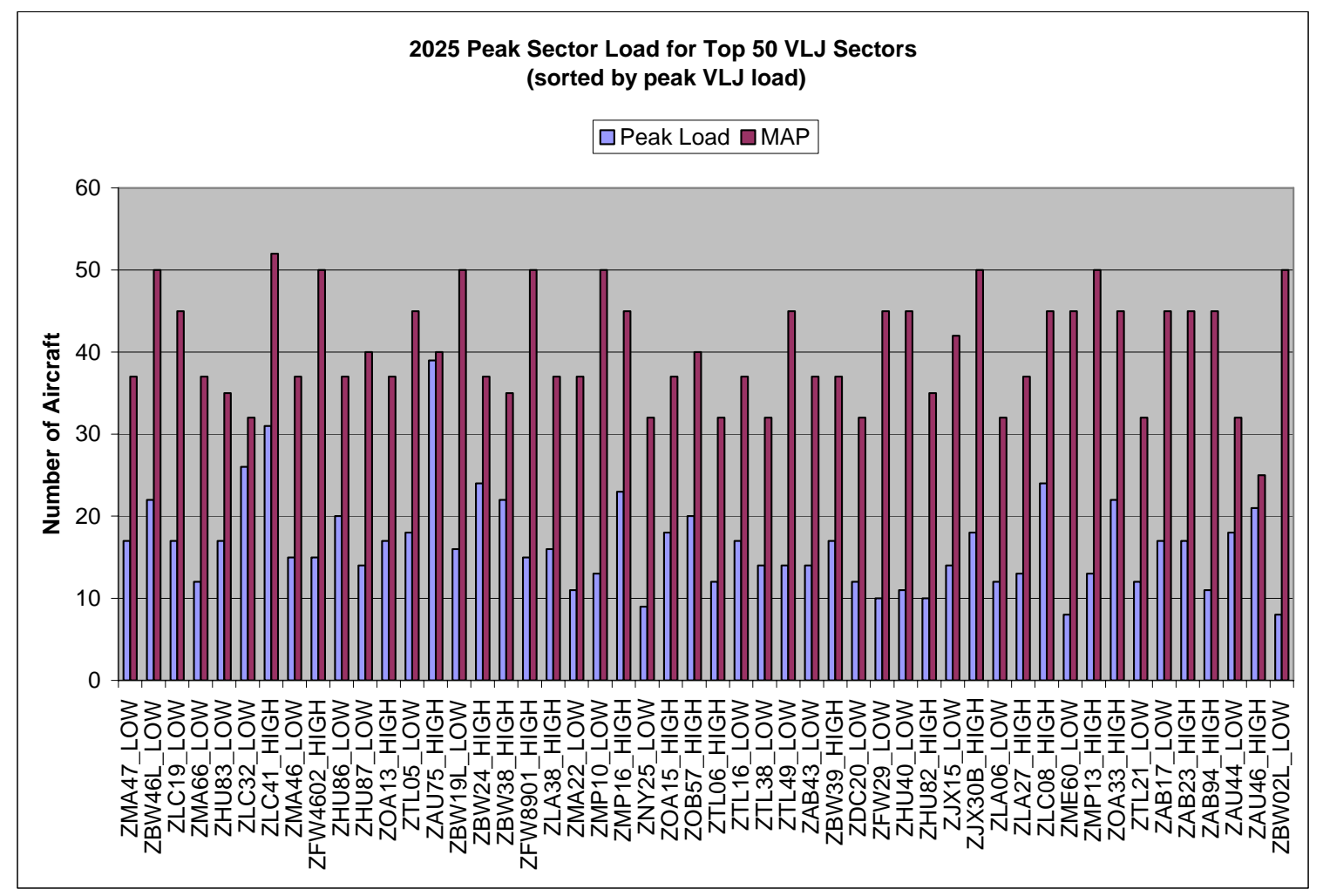

Figure 14. 2025 Peak Sector Load for Top VLJ Sectors (2.5X Sector Capacity)

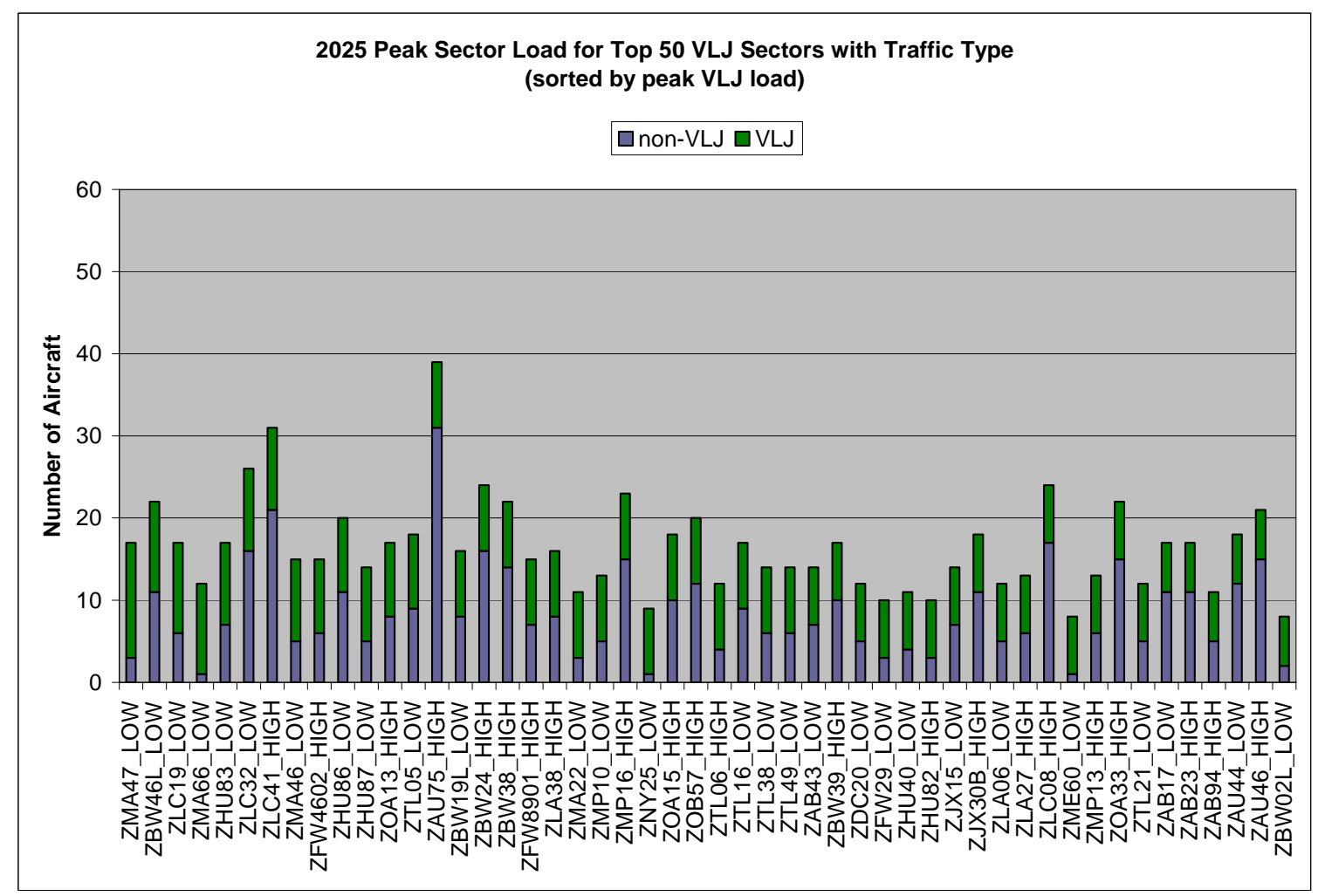

Figure 15. 2025 Peak Sector Load for Top 50 VLJ Sectors with Traffic Type 


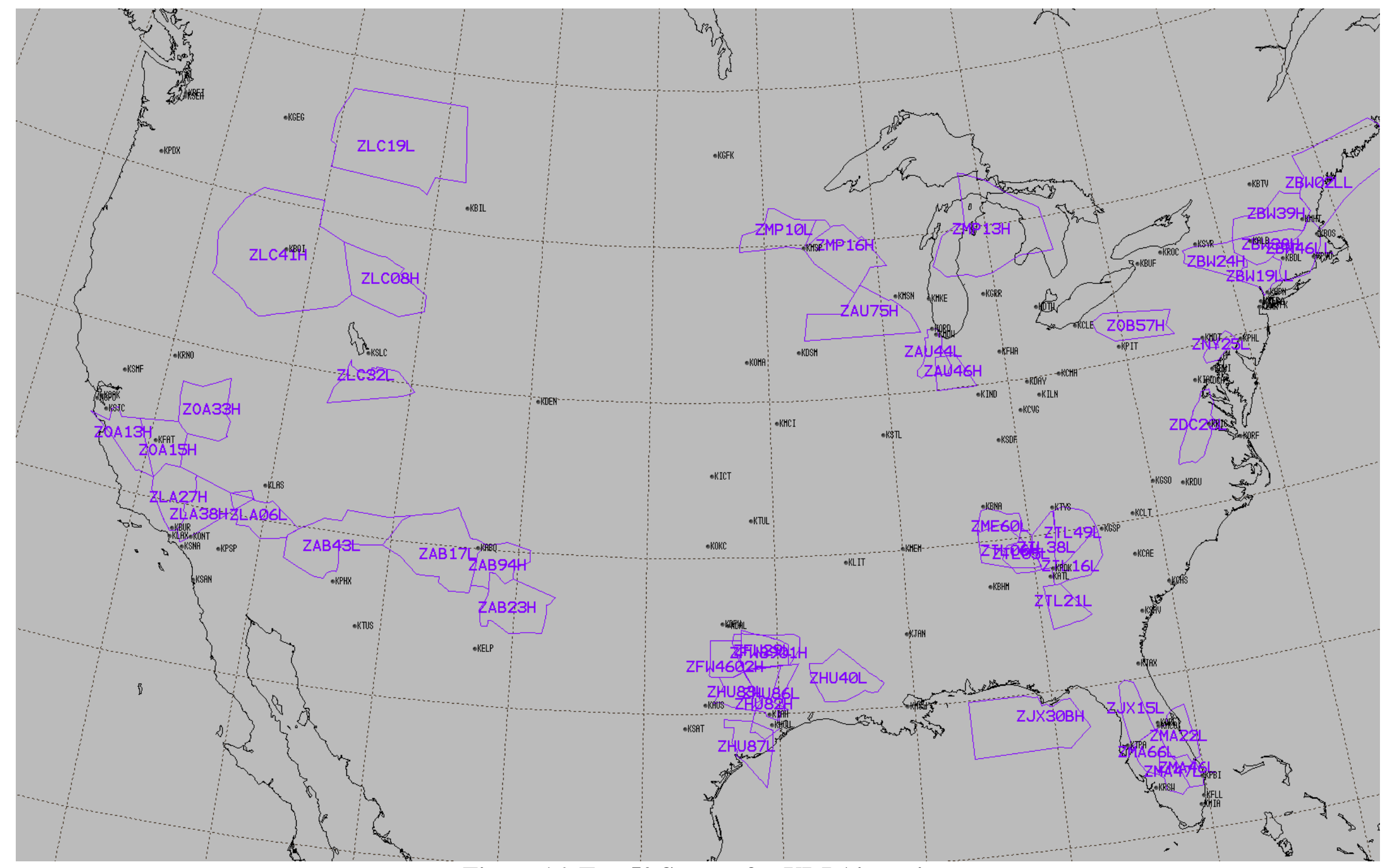

Figure 16. Top 50 Sectors for VLJ Air-taxis 


\section{En-route Conflicts Analysis}

The en-route conflict detection algorithm in ACES was set to report a conflict when aircraft are separated by less than $1000 \mathrm{ft}$ in altitude and less than $5 \mathrm{~nm}$ in distance. NextGen expects future technology to enable en-route minimum lateral separations to be reduced; this was not evaluated in this study.

The theoretical increase in the number of conflicts between $n$ aircraft randomly distributed uniformly in the airspace is proportional to $n^{*}(n-1)$, since this is the number of possible interactions between them. That is, the number of conflicts is approximately proportional to the square of the number of aircraft per unit volume for large values of $n$.

Of course aircraft are not uniformly distributed, groups of like performance-aircraft flying similar routes will prefer similar cruise altitudes and certain airspace regions are much more congested than others. However, the theoretical relationship provides a useful check for the simulation results.

Table 9 below shows the number of times an aircraft of each category was involved in a conflict for the 2004 baseline and the 2025 flight data sets with and without VLJs. The results are for a sector capacity of 2.5X; this was determined from delay analysis to be sufficient to accommodate the 2025 demand.

There is a very substantial increase in potential conflicts between the 2004 and the 2025 flight data sets. Table 10 shows that the potential conflicts increased by a factor of $4.9 \mathrm{X}$ for the flight data set without VLJs and by 5.3X for the 2025 flight data set with VLJs compared to the theoretical factors of 3.9X and 5.7X. Discrepancy with theory may be explained by the non-uniform distribution of flights within the airspace.

Of specific interest to this study is the increase in conflicts due to the additional VLJ traffic. Simulation results showed an increase of nearly 8\%; see Table 11 . This is quite a substantial increase. However, the addition of VLJ air-taxi flights increased the total number of flights by a factor of $1.2 \mathrm{X}$ so the square of the demand would suggest $1.4 \mathrm{X}$ increase in potential conflicts should occur. The much lower increased observed from simulation is because the majority of VLJs in the 2025 flight data set generated are flying at lower altitudes than most commercial traffic, so the potential for conflicts is reduced.

The largest increase in potential conflicts was for GA traffic, 4.8\%. The increase in commercial aircraft potential conflicts was less at 3.2\%. This indicates that VLJs interact more with other VLJs and other GA traffic than with commercial traffic. This is due to the difference in the typical cruise altitudes, with VLJ air-taxis mainly flying lower than the typical commercial aircraft during the cruise phase of flight; see Table 7. 


\begin{tabular}{|r|r|r|r|r|r|}
\hline & Commercial & GA & Cargo & VLJ & Total \\
\hline 19 Feb 2004 & 4299 & 789 & 176 & 0 & 5264 \\
\hline 2025 & 17633 & 7220 & 1017 & 0 & 25870 \\
\hline 2025 with VLJ & 18205 & 7569 & 1037 & 1098 & 27909 \\
\hline
\end{tabular}

Table 9. Total Potential Conflicts by Operator Type

\begin{tabular}{|r|l|l|lr|}
\hline & $\begin{array}{l}\text { 2025 without } \\
\text { VLJ compared } \\
\text { to 2004 }\end{array}$ & $\begin{array}{l}\text { 2025 with VLJ } \\
\text { compared to } \\
\mathbf{2 0 0 4}\end{array}$ & $\begin{array}{l}\text { 2025 without VLJ } \\
\text { compared to } \\
\text { 2025 with VLJ }\end{array}$ \\
\hline $\begin{array}{r}\text { Square of } \\
\text { Demand Ratio }\end{array}$ & 3.9 & 5.7 & 1.4 \\
\hline Conflicts Ratio & 4.9 & 5.3 & 1.1 \\
\hline
\end{tabular}

Table 10. Growth in Potential Conflicts Compared to Growth in Demand

\begin{tabular}{|r|r|r|r|r|}
\hline Commercial \% & GA \% & Cargo \% & All \% & $\begin{array}{l}\text { Total } \\
\text { Additional }\end{array}$ \\
\hline 3.2 & 4.8 & 2.0 & 7.9 & 2039 \\
\hline
\end{tabular}

Table 11. Increase in 2025 Potential Conflicts due to VLJs

\section{Conclusions}

The demand for air transportation, including VLJ air-taxi-operations was forecast for 2025, using the techniques described in this paper. This demand can be accommodated in en-route airspace without incurring additional delays beyond that typical today with an airspace capacity of around $2.3 \mathrm{X}$ to $2.5 \mathrm{X}$ current capacities for the most heavily loaded sectors, based on results from ACES simulation.

This additional airspace capacity is not required throughout the NAS; only $45 \%$ of the enroute sectors analyzed require an increase in capacity and only $19 \%$ need more than $1.5 \mathrm{X}$ current capacity to meet the projected 2025 demand, including VLJ traffic, based on results from ACES simulation.

The additional VLJ air-taxi flights forecast for 2025 will not cause any significant increase in delay to commercial air traffic due to en-route airspace congestion, if the airspace capacity required to accommodate the commercial traffic is achieved. If significantly less than this capacity is available then all traffic will experience increased delays and if only $1.5 \mathrm{X}$ current airspace capacity is achieved then VLJ traffic will have a 
significant additional impact on those sectors that would in any case be overloaded by other traffic.

The majority of the sectors with most VLJ traffic are not the busiest sectors in the NAS. This is due to both the different origin-to-destination routes favored by VLJ air-taxi operations compared to commercial airline traffic and also to the lower cruise altitudes of VLJs. The forecast demand for VLJ flights in 2025 can more than double the peak aircraft count in some of the busiest sectors for VLJ flights. Simulation results indicated that this did not increase en-route delays, since these sectors were not overloaded. VLJ traffic did not require a significant level of en-route capacity increase over that needed to serve the otherwise projected 2025 air traffic.

Even with sufficient airspace capacity to accommodate the demand based on negligible additional delay, VLJ air-taxi operations will increase the potential for conflicts. The additional traffic leads to an almost $8 \%$ increase in total potential en-route conflicts and around a 3\% increase in potential en-route conflicts involving commercial flights, using today's separation standards. This increase in potential conflicts would be a significant additional burden on air-traffic controllers if the conflicts were resolved using today's techniques.

The number of potential conflicts determined from simulation, increases by a factor of 4.9X, even without VLJ air-taxi flights, compared to the 19 Feb 2004 baseline. This level of conflicts will require an air traffic system design that is capable of resolving conflicts with much less human intervention than that required today.

The JPDO CONOPS for NextGen envisages that generation of conflict resolutions will be highly automated. NextGen envisages that separation assurance functions may be delegated to the flight-deck for some air traffic operations in some regions of airspace. VLJ aircraft incorporate the latest navigation and flight management equipment and may be good candidates for equipage with a flight-deck based system for separation assurance.

In addition, most VLJ air-taxi flights are projected to be relatively short range, compared to commercial air-carrier flights. This means that most of the air-taxi traffic will fly at altitudes below the typical cruise altitudes of the air-carrier traffic. This separation of cruise altitudes between VLJ aircraft being used as air-taxis and air-carrier aircraft, due to different modes of operation, leads to fewer potential en-route conflicts between these categories of aircraft than would otherwise be the case. This may be an important factor; large commercial aircraft have cruise speeds that are typically $30 \%$ to $40 \%$ faster than the maximum cruise speed of a VLJ aircraft. Mixing traffic operating at significantly different speeds may otherwise have led to a greater number of conflicts arising from overtaking aircraft.

If the generation of conflict resolutions advisories is highly automated or VLJ air-taxi aircraft can self-separate for the majority of flights, then the additional conflicts caused by VLJ air-taxi flights may not present a significant additional burden on NAS resources. 
If this is the case and airspace capacity is increased to the extent necessary as determined from this study, then the additional VLJ air-taxi operations can be accommodated in the en-route NAS with minimal effect on commercial air traffic.

\section{References}

1. The FAA Aerospace Forecast for fiscal years 2007 - 2020 http://www.faa.gov

2. Air Transport Association http://airlines.org/

3. Concept of Operations for the Next Generation Air Transportation System, DRAFT 5, February 28 - 2007,Version 1.2, Joint Planning and Development Office

4. Small Aircraft Transportation System http://sats.nasa.gov/

5. “Per-Seat, On-Demand” Jet Services (white paper), DayJet Corporation, 1801 South Federal Highway, Suite 100, Delray Beach, Florida 33483, www.dayjet.com

6. The Economic Impact of Very Light Jets, CRA International, D09002-00, May 2006

7. Viken, J., Dollyhigh, S., Smith, J., Trani, A., Baik, H., Hinze, N., Ashiabor, S., Utilizing Traveler Demand Modeling to Predict Future Commercial Flight Schedules in the NAS, AIAA Meeting Papers on Disc, Volume 11,No.17, AIAA, Reston, VA, 2006

8. Smith, J., Dollyhigh, S., Future Air Traffic Growth and Schedule Model, NASA/CR2004-213027, Jan. 2004

9. Airbus Global Market Forecast, 2005 to 2024 http://www.airbus.com/en/myairbus/global_market_forcast.html

10. Smith, J., The Effects of Very Light Jet Air-taxi Operations on Commercial Air Traffic, NASA/CR-2006-214519

11. FAA Operational Evolution Plan version 5, 2004 http://www.faa.gov

12. CDRL 17 Airspace Concept Evaluation System (ACES) Software User Manual, 31 October 2005, Contract Number: NNA05BE01C, Prepared by Raytheon ACES Team, 1001 Boston Post Road, Marlborough, MA 01752-3789 